\title{
Article \\ Interannual Variability of the Congo River Plume-Induced Sea Surface Salinity
}

\author{
Meike Sena Martins * and Detlef Stammer
}

check for updates

Citation: Martins, M.S.; Stammer, D. Interannual Variability of the Congo River Plume-Induced Sea Surface Salinity. Remote Sens. 2022, 14, 1013. https://doi.org/10.3390/rs14041013

Academic Editors: Philippe Waldteufel, Yann H. Kerr and Christine Gommenginger

Received: 6 January 2022

Accepted: 15 February 2022

Published: 19 February 2022

Publisher's Note: MDPI stays neutral with regard to jurisdictional claims in published maps and institutional affiliations.

Copyright: (C) 2022 by the authors. Licensee MDPI, Basel, Switzerland. This article is an open access article distributed under the terms and conditions of the Creative Commons Attribution (CC BY) license (https:// creativecommons.org/licenses/by/ $4.0 /)$.
Center für Erdsystemforschung und Nachhaltigkeit-CEN, Universität Hamburg, Bundesstr. 53, 20146 Hamburg, Germany; detlef.stammer@uni-hamburg.de

* Correspondence: meike.sena-martins@uni-hamburg.de

\begin{abstract}
Based on satellite surface salinity (SSS) observations from the SMOS, Aquarius and SMAP missions, we investigate the interannual SSS variability during the period from 2010 to 2020 in the Gulf of Guinea, impacted by the Congo River run-off. Combined with in situ data, the available 11 years of satellite salinity data suggest that the plume of Congo run-off primarily spreads into western directions, leading to reduced SSS. A fraction of it also shows a coastal southward extent subject to interannual variability influenced by coastal trapped waves. The low-salinity water is associated with high values of net primary production, confirming the riverine origin of the nutrient rich plume. No correlation can be found between the plume patterns and the different upwelling strengths in the subsequent upwelling months, nor could a correlation be found with the occurrence of the Benguela Niños. Linking the occurrence of a barrier layer to the occurrence of low-salinity plumes remains difficult, mainly because of the sparseness of in situ data. However, the influence of the low-salinity layer is evident in its stronger stratification and an increased available potential energy.
\end{abstract}

Keywords: satellite oceanography; sea-surface salinity; coastal trapped waves; eastern boundary upwelling system

\section{Introduction}

The region off the southwestern coast of Africa is one of the world's most productive eastern boundary upwelling regions (EBUS). In this region, the interannual variability of the near-surface surface temperature field, exceeding $2^{\circ} \mathrm{C}$ above or below the seasonal mean, also known as Benguela Niños or Niñas [1,2] (and references therein), weakens or enhances the strength of the upwelling. On interannual timescales, these temperature anomalies have been shown to be remotely forced by equatorial Kelvin waves, which travel along the equatorial wave guide to the east after their genesis by subsequently relaxing western equatorial winds and propagate poleward as coastally trapped waves (CTW) along the coast of Africa. These waves alter the thermocline depth and thus the upwelling processes along the eastern coasts, as in Reference [3]. However, regional effects such as variations in the local wind field could also play a role in the interannual variation in the upwelling [4].

Respective interannual temperature anomalies are frequently associated with sea level anomalies and sea-surface temperature (SST) anomalies [5,6]. The question of to what extent they are also associated with sea-surface salinity (SSS) variability received attention only recently after the launch of the SMOS, SMAP and Aquarius satellite missions. Several previous studies mention the existence of a dispersion of low-salinity plumes away from the Congo River; however, these studies were only based on the sparse in situ data from single cruises, e.g., References [7-9]. More recently, the authors of [10] analyzed the seasonal variability of the SSS in the Gulf of Guinea (GG) and established a climatological salinity budget in the southeast and tropical Atlantic Ocean using the SMOS dataset covering the period from 2010 to 2017 , i.e., based on 8 years of satellite data. The study revealed 
that the Congo River discharge (CRD) is the dominant fresh-water forcing for the area off the Angolan coast. Its subsequent zonal advection and vertical mixing of the fresh-water plumes are, therefore, important processes, involved in setting the salinity tendency off the source region. However, closing the salinity budget remains difficult and incomplete. The extent to which the Congo River run-off influences the salinity, and thus the stratification and heat budget in the region off the Angolan coast, remains an open question. Moreover, the degree to which salinity anomalies foster heat anomalies in this region is also still under investigation based mostly on modeling results, as in Reference [11]. The occurrence of the Congo River freshwater plumes and their variability, therefore, remain of high interest when characterizing the hydrography in the eastern tropical Atlantic area and identifying the causes of the occurrence of coastal temperature anomalies off the Congo River.

After the Amazon River, the Congo River provides the second largest fresh-water discharge into the world ocean. Its river mouth is located in the eastern tropical Atlantic Ocean at about $6^{\circ} \mathrm{S}$ at the African coast, i.e., at the northern rim of the coastal upwelling areas there. The Congo River freshwater plume is mostly directed west-northwest [12], reaching $800 \mathrm{~km}$ offshore during the austral summer. In combination with minor rivers nearby, the Congo River run-off leads to a considerable freshening of the surface salinity in the tropical eastern Atlantic. Since the river discharge is dominated by an annual cycle, it also causes a pronounced cycle in the regional near-surface salinity $[13,14]$. The authors of [15] identified an amplitude of the annual cycle from in situ data, which exceeded 1.8 in salinity. However, surface salinity variability in the gridded (objectively analysed) in situ data has been underestimated in comparison to satellite-derived SSS data [16].

The Congo River is also the 2nd largest source of terrestrial organic carbon [17], with maximum concentrations of dissolved organic carbon (DOC) occurring in phase with the maximum discharge. As a result, the river plume is not only characterized by a salinity minimum but also by a chlorophyll maximum, occurring about $25 \mathrm{~km}$ off the river mouth, and presumably produced there by the production of new POC and DOC [18]. The authors of [19] found a high correlation between the salinity and chlorophyll signal in 2010; likewise, the authors of [8] showed an agreement between ocean color from the period 2002-2009 and ocean salinity pattern from a 2005 model output. However, both studies again show that we still lack detailed knowledge of observed SSS variability in this region. Moreover, detailed knowledge of interannual salinity variability is also necessary for model improvements and assimilation studies; see Reference [20].

General ocean circulation models rely on boundary conditions, which are not well known, especially in the case of salinity, so that ocean simulations are commonly restored to climatological salinity fields. SSS is the imprint of fresh-water flux forcing by river runoff and atmospheric-ocean interchange, i.e., precipitation and evaporation. Both forcing strengths are subject to high uncertainty; therefore, knowledge of SSS fields and their variability can help to adjust the boundary conditions in ocean simulations. The authors of [21] found that most Coupled Model Intercomparison Project-Phase 5 (CMIP5) earth system models do not show satisfactory skills in reproducing the distribution of monthly river discharge, and their interannual trends and appear to largely overestimate the streamflow in terms of intra-annual patterns, up to $4-5$ times for some months, consequently affecting the simulation of sea-surface salinity and temperature and ocean circulation and climate.

Ocean in situ data, especially salinity profiles, from the vicinity of the Congo River mouth are sparse; therefore, a long-term analysis of the Congo River plume dispersion remains difficult. However, since 2010, the SMOS, Aquarius and SMAP satellites have provided maps of SSS with uncertainties, especially near to land. A recent dataset of SSS produced by the Climate Change Initiative at the European Space Agency (ESA CCI), combining the three satellite missions, shows reasonable values even close to the coast.

Building on previous studies, the purpose of the present study is to describe the interannual variability in the SSS in the GG and the eastern tropical North Atlantic in much more detail than was previously possible. By using satellite SSS fields, the paper will provide a detailed overview of the interannual and intra-seasonal variability in the 
northern Benguela upwelling region by highlighting the co-variance of the different surface parameters. Due to the low salinity of the riverine water, the stratification is assumed to be influenced by a so-called barrier layer, which might prevent the surface layer from being cooled from below; enhanced stratification might potentially influence the upwelling intensity and provide particular local conditions for the propagation and breaking of internal waves and, thus, enhanced mixing [22]. A set of in situ data from near to the African coast (the "Nansen" dataset [23]) will be used to validate the satellite data in this region and to carry out the analysis of the SSS variability.

The remaining paper is structured as follows: First, the used data will be described and their sources will be listed. The data section also comprises the validation of the near-coastal satellite salinity data. The annual and semiannual SSS cycle and its phase, as well as its anomalies, will be updated and interannual anomalies will be shown. The interannual sea surface salinity will be shown in parallel with interannual anomalies from other surface parameters such as SST and net primary production. Moreover, the sparse in situ data are analysed to the show the low-salinity plume's potential consequences for the stratification. Possible causes of the interannual SSS variability will be analyzed and related to the interannual anomalies and events of Benguela Niños and Niñas. The causes of the occurrence of anomalies will be discussed in the context of the recent studies.

\section{Materials and Methods}

\subsection{Input Datasets}

\subsubsection{Satellite Data}

ESA CCI sea-surface salinity: The sea-surface salinity (SSS) data are a composite of the bias-corrected sea-surface salinity from the European satellite mission Soil Moisture and Ocean Salinity SMOS (from 2010 to 2019) and the NASA missions Aquarius (from 2012 to 2015) and SMAP (from 2015 to present). The quality of the satellite-derived salinity data is described in Reference [24], and the data were provided by the ESA Climate Change Initiative (CCI) [25], available at https://data.ceda.ac.uk/neodc/esacci/ sea_surface_salinity/data/v03.21/7days (accessed on 11 November 2021).

The Net Primary Production (NPP) dataset used in this study cover the period from July 2002 to July 2020 on monthly means and is freely available online http:/ / sites.science. oregonstate.edu/ocean.productivity/index.php (accessed on 10 September 2021). The data fields have a horizontal resolution of $1 / 6^{\circ}$ but are interpolated on a $0.25^{\circ} \times 0.25^{\circ}$ spatial grid to match the SST anomalies. The NPP data are based on the Eppley Vertically Generalized Production Model, which uses MODIS chlorophyll, SST data, and SeaWiFs photosynthetically available radiation and estimates of the euphotic zone depth.

Improved near-surface velocity data for the global ocean were based on dynamic considerations and absolute drifter velocities. The data represent the mean velocity in the upper 30 m (ESR. 2009. OSCAR third-degree resolution ocean surface currents. Version 1, PO.DAAC, CA, USA, http:/ / dx.doi.org/10.5067/OSCAR-03D01, accessed on 8 June 2021).

To estimate the monthly wind fields, we used the Earth System Model data produced by the ECMWF (ERA5) Wind, an atmospheric reanalysis product with a horizontal resolution of $0.281^{\circ} \times 0.281^{\circ}$ [26].

The precipitation in the southeast Atlantic was estimated using several pieces of data: data from the Integrated Multi-satellitE Retrievals for the Global Precipitation Measurement Mission (IMERG) data [27], and data of the Global Precipitation Climatology Project (GPCP [28]).

The evaporation data were downloaded from https: / / oaflux.whoi.edu (accessed on 22 November 2021). They were developed from the optimal synthesis of satellite wind and SST observations and atmospheric reanalysis of air temperature and humidity. The products are available at a $1^{\circ}$ resolution from 1958 to the present [29].

Sea-level anomalies were used, as they result from reprocessed and gridded seasurface height observations provided by CMEMS, Credits: E.U. Copernicus Marine Service Information, https: / / resources.marine.copernicus.eu/?option=com_csw\&view=details\& 
product_id=SEALEVEL_GLO_PHY_CLIMATE_L4_REP_OBSERVATIONS_008_057, accessed on 12 April 2021.

\subsubsection{In Situ Data}

In situ data consist in a collection of profile data, made available by [30]. We downloaded the version EN4.2.1 from the website www.metoffice.gov.uk/hadobs/en4 (accessed on 5 July 2021) and applied the filter of 'good' to the profiles. An additional quality check filtered out the profiles that did not provide data in the upper $10 \mathrm{~m}$ or those with unrealistic salinity values, which led us to exclude $11 \%$ of the profiles. Moreover, we used local, in situ data, which were not yet involved in the EN4 data from Nansen cruises: in situ temperature and salinity profiles from the $R / V$ Dr. Fridtjof Nansen cruises [23], available at the data center PANGAEA under https:/ / doi.pangaea.de/10.1594/PANGAEA.886492, accessed on 18 November 2018).

Congo River discharge data, from a station in Congo at /Brazzaville, a station $400 \mathrm{~km}$ upstream of the Congo River mouth but without any noteworthy inflow downstream of Brazzaville, were downloaded from the ORE hydrobam project (https: / /hybam.obs-mip. $\mathrm{fr} /$ data, accessed on 18 May 2020).

\subsection{Methods}

To calculate the interannual anomalies in various scalar properties, the monthly mean annual cycle was interpolated to the time vector of the original time series and subsequently subtracted from the original SSS, SST, NPP, velocity and wind time series. The anomalies thus comprise a shorter variability than annual variability, i.e., sub-seasonal variability, as well as the interannual variability. In case of the SSS data, the time series comprises 10 years whereas the SST and NPP data comprise time periods from 1980 or from 2002 until 2020 , respectively. Note that the monthly mean cycle is only representative of the period of data availability. In the case of SSS, the interannual variability was found to be as high as the seasonal variability; therefore, the anomaly from the long-term mean was also used.

The mixed-layer depth based on a temperature threshold $\left(\mathrm{ML}_{\mathrm{t}}\right)$ was calculated by linear interpolation with a threshold of $0.5^{\circ} \mathrm{C}$ to the temperature value at the uppermost value but with a minimum depth of $1 \mathrm{~m}\left(\mathrm{~T}_{1}\right)$. The mixed-layer depth, based on the density gradient $\left(\mathrm{ML}_{\mathrm{r}}\right)$, was calculated as the depth at which the potential density $\sigma$ increased by a value corresponding to the salinity near the surface, and $\mathrm{T}_{1}$ reduced by $0.5{ }^{\circ} \mathrm{C}$ : $\Delta \sigma=\sigma\left(\mathrm{T}_{1}-0.5, \mathrm{~S}_{1}, 0\right)-\sigma\left(\mathrm{T}_{1}, \mathrm{~S}_{1}, 0\right)$. This method is similar to that of Reference [31], but we used a temperature threshold of $0.5{ }^{\circ} \mathrm{C}$ instead, as was conducted by the authors of [11]. This density increase was, on average, $0.15 \mathrm{~kg} / \mathrm{m}^{3}$.

The barrier layer (BL) is the positive difference between these mixed-layer depths: $\mathrm{BL}=\mathrm{ML}_{\mathrm{t}}-\mathrm{ML}_{\mathrm{r}}, \mathrm{BL}>0$. The $M \mathrm{~L}_{\mathrm{r}}$ considers the density stratification due to salinity, whereas $\mathrm{ML}_{\mathrm{t}}$ is the depth of the isothermal layer. If there is no salinity stratification in the isothermal layer, these ML depths are identical and $\mathrm{BL}=0$. In the eastern tropical Atlantic, the thermocline and pycnocline are quite sharp, and the vertical gradients are very strong. We wanted to catch the barrier layer that is eventually caused by the riverine, low-salinity water. This riverine water is some deci-grades warmer than the surrounding oceanic water; moreover, tropical water is advected southward, strengthening the vertical temperature gradient in this region. We used the temperature criterion of 0.5 to discern the warm, low-salinity upper layer from the isothermal mixed layer. Most in situ profiles revealed a vertical resolution of $5 \mathrm{~m}$. The linear interpolation of the profile data to $1 \mathrm{~m}$ implies an uncertainty with the calculated mixed-layer depths; therefore, we only considered a BL thicker than $6 \mathrm{~m}$ as reliable.

\section{Results}

\subsection{Comparison of Near Coastal Satellite Salinity Data with In-Situ Data}

The CCI + SSS satellite SSS retrievals used here have been globally validated and their accuracy was stated to be better than 0.15 in most areas [25]. However, uncertainties in the 
satellite-derived salinity data remain high near coastlines due to land contamination of the signal there [24].

In Figure 1, the CCI + SSS salinity data are compared with in situ salinity measurements. To this end pairs of data collected from both datasets were identified in $0.5^{\circ} \times 0.5^{\circ}$ grid boxes over the study region, considering only data within a temporal time window of one week. As can be expected, maximum salinity differences between both datasets were found near the Congo River mouth, where the differences exceeded 1 in magnitude (Figure 1a). Apart from the enhanced near-coast SSS errors mentioned above, differences can result from a physical mechanism, such as vertical salinity gradients off the river mouth. Satellite data represent the top centimeter of the water column, whereas in situ data are measured in 2 to $5 \mathrm{~m}$ depth of the water column. Moreover, the satellite-derived SSS maps represent space-time averages, whereas the in situ data are punctual measurements in space and time. We note that the Nansen data used for this coastal validation are truly independent, as these data were not used for the bias-correction process of the satellite-derived SSS data.

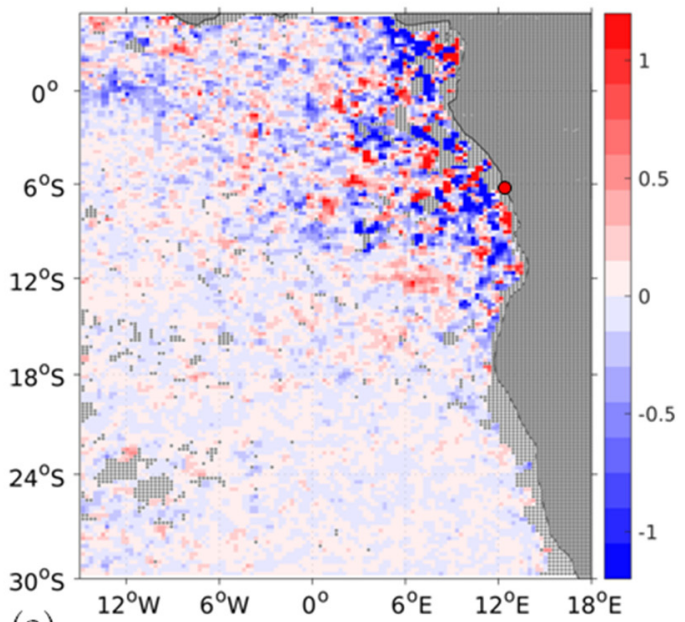

(a)

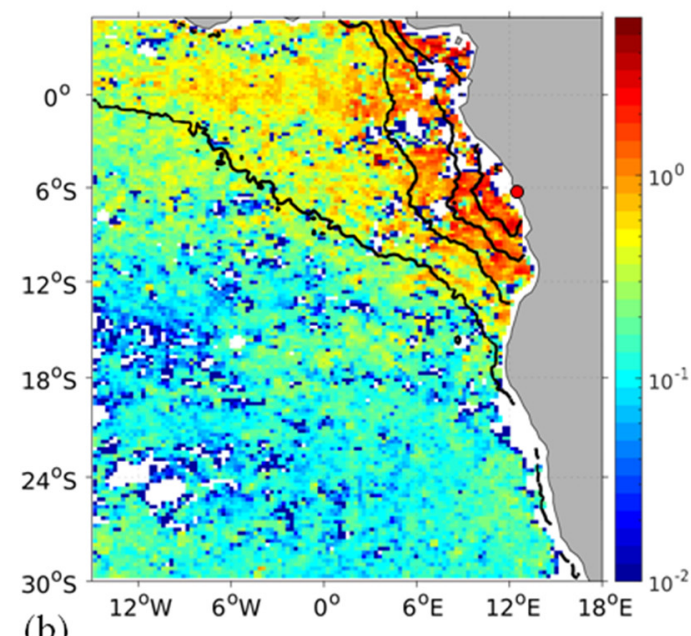

(b)

Figure 1. Salinity differences from CCI + SSS to in situ data (Nansen and Argo profiles): (a) time-mean salinity difference from the period from January 2010 to December 2019 (grey stippling mark in situ data void areas); (b) RMSD in color shading (logarithmic color scale, white areas indicate no data); and STD of the CCI + SSS as contour lines (at 0.4, 0.8, 1.2 and 1.6, increasing from open ocean to the coast). The red dot marks the Congo River mouth.

The root mean square differences (RMSD, shown in Figure 1b) are high in the region of the Congo River plume and the GG, but decline toward the open ocean, and especially toward the south, where the RMSD does not exceed 0.5. Lines of constant SSS variability (STD) are overlayed as black contour lines in Figure 1b. It can be seen that high SSS variability coincided with the area of high RMSD. In contrast, in the region south of $15^{\circ} \mathrm{S}$, mean differences and RMSD values were lower. RMSD values were enhanced in the months from February to April and October (not shown), when the plume was present. The authors of [16] attribute the higher RMSD during periods of low SSS to the inadequate sampling of the in situ measurements to capture the run-off-induced freshwater plume associated with stronger spatial and temporal variability following the high-discharge season. We conclude that the differences in in situ salinity are mainly due to the differences in sampling and vertical salinity gradients, but that, in general, CCI + SSS are trustworthy in the near-coastal areas.

\subsection{Annual and Semi-Annual Salinity Variability}

In this section, we summarize the main features of the seasonal salinity variability in comparison to its potential drivers. The amplitude of the annual and semiannual 
cycle, and phase of the salinity minimum in the CCI + SSS over the GG, are shown in Figure 2. The lowest salinity occurred between November and March in the equatorial and south-equatorial regions off the tropical western African coast, mainly due to the river discharge, mainly from the Niger River located at $3^{\circ} \mathrm{N}$ into the eastern GG and the Congo River at $6.2^{\circ} \mathrm{S}$. Enhanced tropical precipitation also contributed to the salinity minimum during this period. While the maximum discharge of the Niger River and the rivers in Cameroon and Gabon, as well as maximum precipitation, occurred in October [11,32], the maximum discharge of the Congo River (as measured at a station in Kinshasa) occurred in December. It is assumed that the phase shift in SSS, shown in Figure $2 \mathrm{~b}$ relative to the maximum freshwater sources, resulted from the fact that the drainage areas on the African continent are influenced by the seasonal march of the Intertropical Convergence Zone (ITCZ); nevertheless the authors of [32] claimed that this ITCZ paradigm does not explain the seasonal cycle in this region, while other processes such as Madden Julian Oscillation and Indian Monsoon influence the variability in the equatorial, western African region. According to the authors of [33] and [10], precipitation at $6^{\circ} \mathrm{S}$ over the ocean is not of any relevance to the seasonal decrease in ocean salinity; instead, the CRD alone suffices to explain the observed SSS structure and variability. The observed spreading of the associated low-salinity plume across the eastern South Atlantic takes some weeks, meaning that time of minimum salinity propagates from November southward along the coast of the GG, reaching $15^{\circ} \mathrm{S}$ latitude in April/May. The Congo River freshwater plume also extends zonally along $6^{\circ} \mathrm{S}$, showing minimum SSS near the coast in December and January, and at about $4^{\circ} \mathrm{W}$ in June/July.

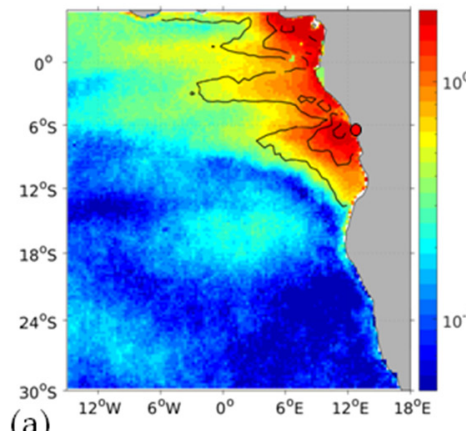

(a)

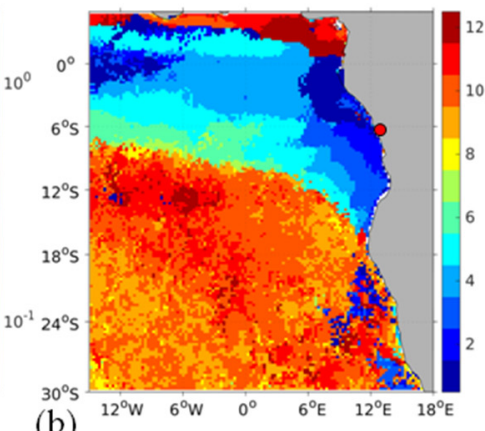

(b)

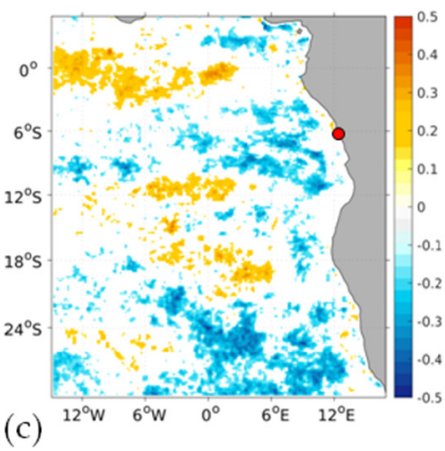

Figure 2. (a) Amplitude of the annual (color) and semi-annual (black contours at 0.25, 0.5 and 1); (b) phase (month of minimum SSS) of the CCI + SSS seasonal cycle in the tropical east Atlantic Ocean representing the period of 2010 and 2020. (c) Significant correlation index (p-value < 0.05) between the SSS anomaly and the anomaly of the net primary production. Note that the Congo River mouth is situated at $6.2^{\circ} \mathrm{S}$ (marked by a red dot).

Usually, high SSS and high nutrient levels correlate in areas of upwelling (off the Guinea and Namibian coasts and along the equator). In contrast, the correlation between the SSS and NPP anomalies is clearly negative but large in magnitude in the area off the Congo River mouth (Figure 2c), due to the high nutrient riverine input associated with the freshwater inflow there. (Only significant values are plotted, using t-statistics and assuming a normal distribution.) The climatological time series of the two parameters also yields a high negative correlation off the Congo River mouth (not shown). In the open ocean south of the Angola Benguela Front, the NPP is generally low, and the correlation is negative, i.e., highest NPP occurs in the months of low SSS, which are from October to December (Figure $2 b$ ). The area with a slightly positive correlation between the SSS anomaly and NPP anomaly may be a signal of the upwelling in the Angola dome $\left(12^{\circ} \mathrm{S} / 5^{\circ} \mathrm{W}\right.$ to $\left.18^{\circ} \mathrm{S} / 6^{\circ} \mathrm{E}\right)$.

The large size of the Congo Basin beneath the migrating tropical rain belt produces flood waves on the various tributaries that reach the Congo River with different phases [34], thereby modulating the variability of the CRD. Figure 3 shows the respective time series of 
the CRD between 1980 and 2020 at Kinshasa/Brazzaville, showing a clear annual cycle and a small semiannual component. Maximum CRD occurs, on average, early in December, with an std of 9 days; the minimum occurs late in July with an std of 16 days. The maximum river discharge is $5.7 \cdot 10^{4} \mathrm{~m}^{3} / \mathrm{s}$ and the minimum amounts to $2.82 \cdot 10^{4} \mathrm{~m}^{3} / \mathrm{s}$, with an interannual std of only $10 \%$ (i.e., $0.55 \cdot 10^{4} \mathrm{~m}^{3} / \mathrm{s}$ and $0.32 \cdot 10^{4} \mathrm{~m}^{3} / \mathrm{s}$, respectively) for these extreme daily river discharges. The annual mean and std of the total CRD are $3.94 \cdot 10^{4} \mathrm{~m}^{3} / \mathrm{s}$ and $0.9 \cdot 10^{4} \mathrm{~m}^{3} / \mathrm{s}$, respectively; the interannual component comprises about $22 \%$ of the total variability. Assuming an average downstream flow speed of $0.1 \mathrm{~m} / \mathrm{s}$ from Kinshasa/Brazzaville to the $400 \mathrm{~km}$ downstream river mouth at the Atlantic coast, the maximum discharge into the Atlantic Ocean occurs in January, the minimum during mid-August. Deriving a detailed arrival date of the maximum fresh-water discharge from the SSS time series is difficult, because the SSS near the Congo River mouth is continuously low, and the satellite SSS field is only spatially resolved on scales of $50 \mathrm{~km}$, and temporarily resolved for 10 days. Furthermore, the SSS is also dependent on advection and mixing, as well as on the amount of river discharge. Most of the ocean salinity minimum spreads to the west; however, it partially also spreads southward, as revealed here for the first time by the southward progressing coastal SSS minimum.

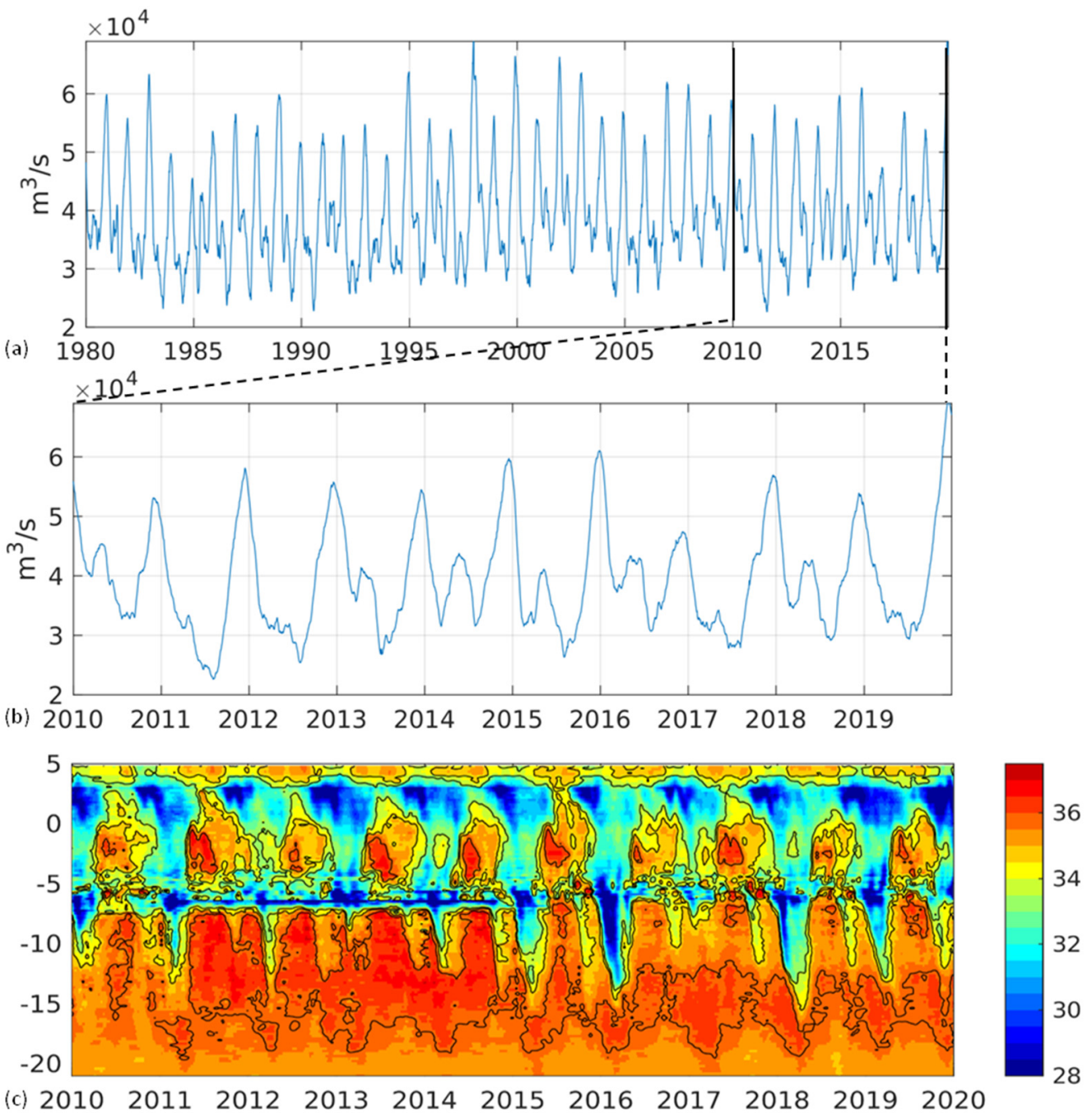

Figure 3. (a) Congo River discharge at a station in Brazzaville (Kongo) $400 \mathrm{~km}$ upstream of the Congo River mouth at $6.2^{\circ}$ S, the long time series from 1980 to 2020 and (b) expansion of panel (a) for the period of SSS data availability, i.e., 2010 to 2020. (c) Sea-surface salinity, zonally averaged from the coast to a distance of $150 \mathrm{~km}$; black contours are given at SSS $=[33.5,34.5$ and 34.8]. 
We note that the average river discharge of about $4 \cdot 10^{4} \mathrm{~m}^{3} / \mathrm{s}$, as calculated here, is about $10 \%$ smaller than that provided by Reference [35], a commonly used river discharge dataset. However, their discharge data represent the period from 1948 to 2000, whereas the present study uses data from 1980 to 2020. Whether this decrease is due to differing precipitation amounts or patterns or due to the different water use in the huge river catchment area over the decades is not a subject of the present study. The authors of [34] state that the anthropogenic influence on the hydrology of the River Congo is small; nevertheless the authors of [36] recently showed a decrease in precipitation until 2017; subsequently, precipitation in late 2019 was exceptionally high, resulting in the highest CRD since 1980.

Figure 3b shows an expansion of the CRD time series for the period 2010-2020, over which the satellite SSS data are available. The SSS, zonally averaged across a 150-km distance along the coast (Figure 3c), shows a similar annual cycle corresponding to the evolution of the CRD, with a minimum salinity between $5^{\circ} \mathrm{S}$ and $10^{\circ} \mathrm{S}$ at the beginning of the year and a secondary but weaker minimum in October at these latitudes (the Congo River mouth is at $6.2^{\circ} \mathrm{S}$ ). Another SSS minimum in the GG (north of the equator) occurs about 2 months earlier, according to the earlier maximum river discharge due to the earlier phase of rainfall. A secondary north equatorial salinity minimum is evident in April, in phase with the secondary minimum off the Angolan coast. The correlation between CRD and the salinity minimum off the Congo River mouth, averaged in the area $100 \mathrm{~km}$ of either side of the coast at $6.2^{\circ} \mathrm{S}$ (not shown), is significant but weak, at only $\mathrm{R}=-0.28$. The low correlation is due to the high salinity variability of $>1$ and presumably due to the influence of mixing and advection.

As can be inferred from the slanted isohalines in Figure $3 c$, the salinity minimum propagates southward along the coast south of $6^{\circ} \mathrm{S}$, presumably by advection. The authors of [37] reported a respective surface current along the coast from February to April and in October. This surface current is a consistent pattern of semiannual circulation initiated by the dynamics of the equatorial circulation, provoking the semiannual occurrence of Kelvin wave propagating as Coastal Trapped Waves (CTW) along the northern and southern African coast. The variability in the coastal current (AC) off Angola and Namibia is partly controlled by the passage of these CTW [37,38]. During Benguela Niños, the AC advects warm tropical waters poleward into the northern Benguela region, impacting the marine ecosystem but also rainfall anomalies [39-41].

As surface velocities are difficult to derive from moorings and ship-borne observations, subsurface current information is mainly available from in situ measurements. The authors of [42] inferred an associated mean southward transport near the shelf break at $11^{\circ} \mathrm{S}$ of only $0.32 \mathrm{~Sv}\left(1 \mathrm{~Sv} \equiv 10^{6} \mathrm{~m}^{3} \mathrm{~s}^{-1}\right)$ from the moored time series available across the shelf and continental slope, which is lower than that estimated by synoptic measurements in older studies. The geostrophic currents derived from the SLA (the Oscar data) have uncertainties near to the coast due to aliasing problems. These data are used here for comparison with the estimates of surface current velocities deduced from the southward spreading of the low-salinity tongue along the Angolan coast. The salinity minimum is used as a tracer, which is considered quasi-conservative during the time in which it is advected southward. Mixing by lateral diffusion and vertical processes is assumed to be slow in comparison to the advection, because the flow is concentrated in the shelf region. Moreover, wind speed is very low, especially in October and February; therefore, wind stress is of minor relevance. Furthermore, the surface mixed layer is sharply separated by a strong vertical density gradient, and the atmospheric freshwater surface flux during these months is very small, and does not lead to any considerable alteration in salinity. With these assumptions, the progress of the low-salinity front can be inferred from the Hovmöller diagram from Figure 3c. Single events of the southward spreading are used to estimate the mean velocity over the weeks.

The southward spreading of low-salinity surface waters from the Congo River plume usually occurred from around March to April, and again during October and November 
(Figure 4). The chlorophyll content of the surface water along the coast was also elevated during these months, corroborating a fluvial origin and causing a high net primary production (not shown). Figure 4 shows the respective yearly evolution of velocity and SSS along the African coast: two dominant periods of geostrophic southward flow (Figure 4a) and low SSS (Figure $4 \mathrm{~b}$, contours) can be identified from January to April and from September to November. These periods are associated with the southward advection of warm water and high sea-level anomaly (SLA, not shown), corresponding to phases of downwelling [23]. The strongest upwelling, though weak at the latitudes off Angola, and northward flow, occurred between May and August, here associated with a high SSS of up to 36. The variability in the meridional flow is plotted as color shading in Figure $4 \mathrm{a}$ and shows the highest variability in the onset of the southward flow over the years. Three patches of high $\operatorname{std}(V)>5 \mathrm{~cm} \mathrm{~s}^{-1}$ in southward flow can be seen in mid-January, the end of February and in April, indicating stronger variability due to coastal trapped waves, which influence the southward flow poleward to $15^{\circ} \mathrm{S}$. These periods of high velocity variability are associated with high salinity variability (Figure $4 \mathrm{~b}$ ). From September to December, the variability was not as high as in the first months of the year; however, mean southward flow in October reached at least $12^{\circ} \mathrm{S}$. The mean low salinity $(\mathrm{SSS}<35)$ derived from the satellite data was advected to at least $13^{\circ} \mathrm{S}$ in both periods and high values of variability with $\operatorname{std}(\mathrm{SSS})>0.8$ reached southward to $15^{\circ} \mathrm{S}$ (Figure $4 \mathrm{~b}$ ). The CRD was at a maximum in January and minimum in August at the river mouth (Figure 4c), and was the cause of the high salinity variability advected along the coast.

\subsection{Interannual Variability of the Alongshore, Southward Spreading}

The in situ data from the Nansen cruises confirm the low-salinity water in the upper surface layer, spreading southward along the coast. The authors of [42] showed that very low surface salinity occurs along $11^{\circ} \mathrm{S}$ in February and March, and again in October. We extend this description to the occurrence of the low-salinity layer along the coast throughout the years based on the same in situ data; to this end Figure 5a,b show monthly and zonal averages of the sections within a coastal distance of $150 \mathrm{~km}$. The calendar date of each section varies through the years; most cruises took place around February and in August (Figure 5d) to catch the main down- and upwelling seasons; however, from October to December, no Nansen cruise took place at all [23]. The velocity contour of $-5 \mathrm{~cm} / \mathrm{s}$ extracted from the Oscar velocity dataset, zonally averaged in a $100 \mathrm{~km}$ band off the African coast, is superimposed onto the salinity averaged in the upper $10 \mathrm{~m}$ (Figure 5a). The figure reveals that the cruises did not always catch the southward flow that eventually began in January, because the cruise took place one or two months later (e.g., in 2004 and 2005) and thus did not measure the very low salinity. A rapid decline in the low salinity is evident in cases when the sections were repeated some weeks later, e.g., in 2006 and 2009. Usually, the cruises in February and March showed patterns of low salinity with a varying southward extent, e.g., in 2001 it reached a latitude of $17^{\circ} \mathrm{S}$ and, in most cases, $13^{\circ} \mathrm{S}$. Unfortunately, the cruises show gaps in measurements south of $13^{\circ} \mathrm{S}$ so that the exact maximum southward reach cannot always be determined from the present data set. Figure $5 b$ shows the continuation of Figure 5 a into the decade of the satellite-derived SSS, with an overlapping time-period of from 2010 to 2014. The blue shading of low SSS corresponds to the low in situ salinity and is associated with poleward meridional velocity from January to April or from October/November of each year. Figure 5c, finally, shows a mean salinity section along the coast in the first months (January to April ) of the years from 1995 to 2014 from the in situ data. 


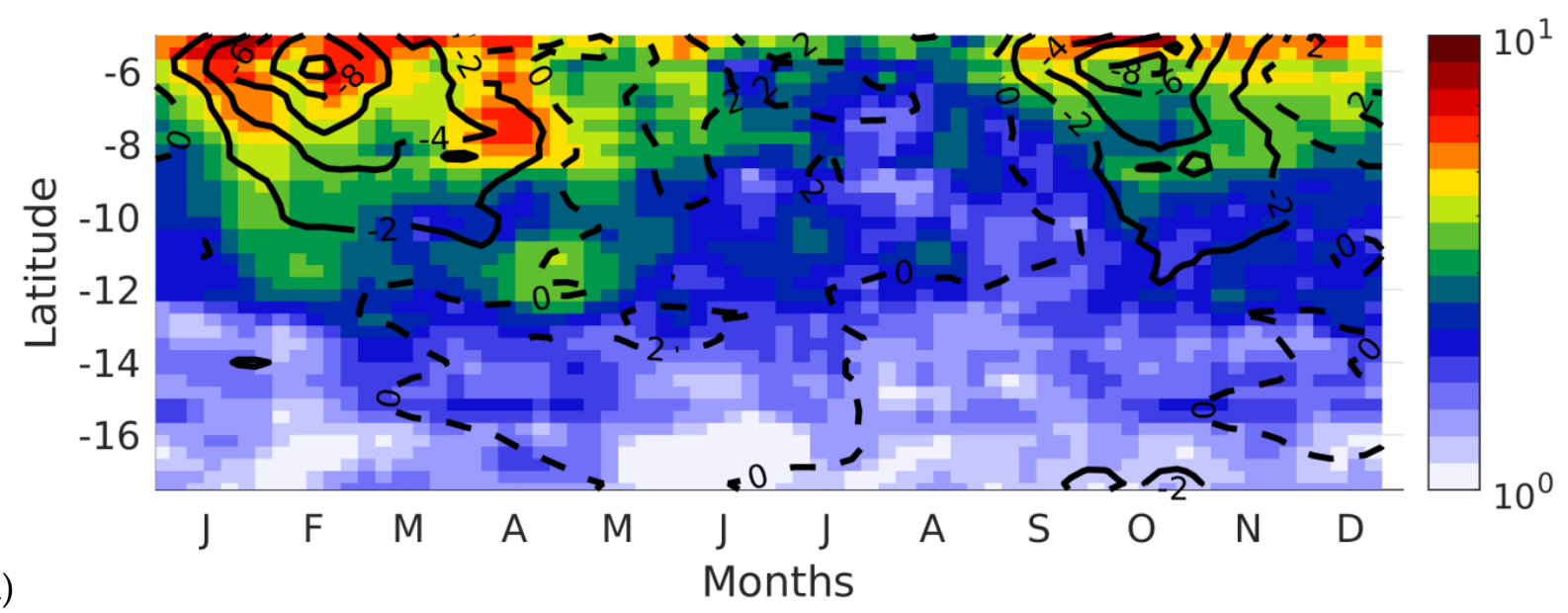

(a)

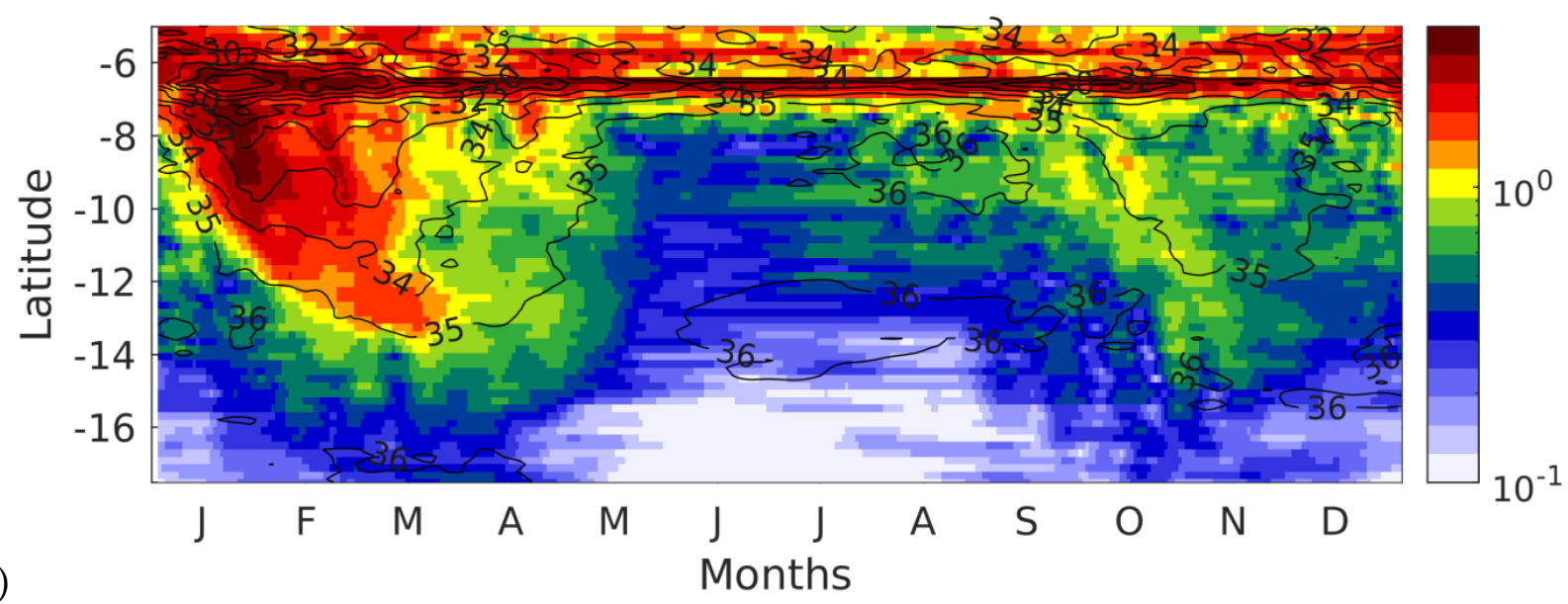

(c)

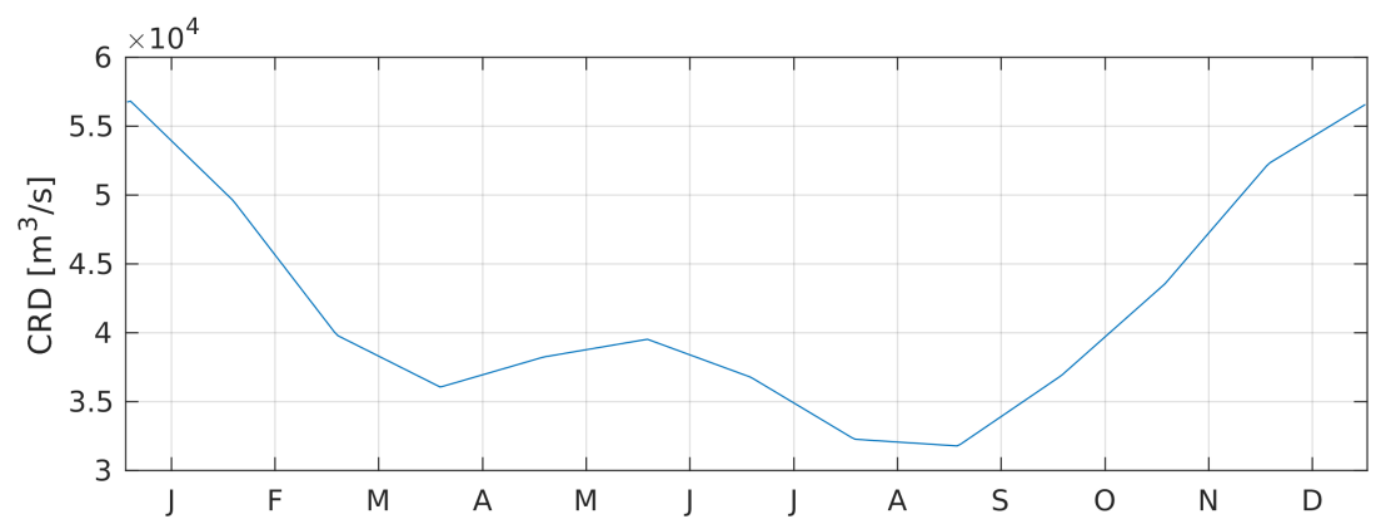

Figure 4. Averaged yearly evolution of (a) the zonally averaged meridional velocity (V, 1993 to 2019, labeled contours in $\mathrm{cm} / \mathrm{s}$; dashed contours indicate northward flow) along the coast with the std of V in color shading ( 1 to $10 \mathrm{~cm} / \mathrm{s}$ ). (b) Averaged yearly evolution of the zonally averaged sea-surface salinity along the coast in the years from 2010 to 2019 (labeled contours, from 28 to 36) with the std (SSS) as color shading. (c) Monthly averaged Congo River Discharge from the gauge station at Kinshasa, shifted by 1 month $\left[\mathrm{m}^{3} / \mathrm{s}\right]$. 

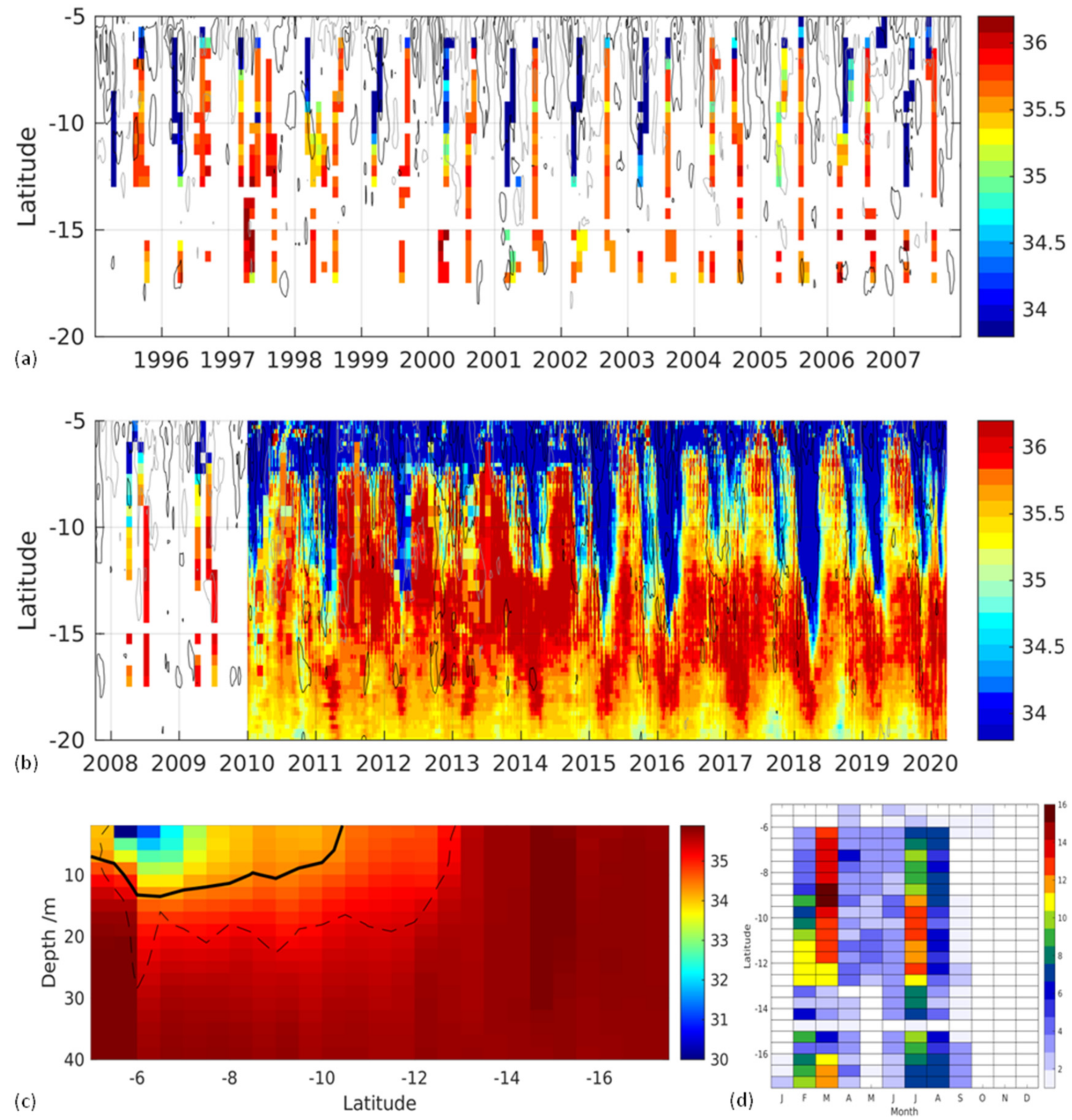

Figure 5. (a) In situ salinity, in the zonally (150 km off the coast) and vertically (the upper $10 \mathrm{~m}$ ) averaged sections along the African coast from 1995 to 2007, and (b) in situ salinity and satellitederived salinity from 2008 to 2020. Contours show the low-passed surface velocity from the Oscar dataset, zonally averaged in the 100-km band off the coast (black contours show southward velocity of -5 and $-10 \mathrm{~cm} / \mathrm{s}$; grey contours show northward velocity). (c) Zonally (150 km off the coast) and temporally averaged section along the Angolan and Namibian coast from in situ data during Nansen expeditions in the first months (Jan to Apr) of the years from 1995 to 2014 . The bold contour shows the mean depth of the isohaline of 34.5 , reaching $10^{\circ} \mathrm{S}$, and the dashed line indicates the $\operatorname{std}(\mathrm{S})$ $=0.5$, i.e., the influence of low-salinity water layer reaches depths of $20 \mathrm{~m}$, southward to at least $13^{\circ} \mathrm{S}$. (d) Data availability of the gridded Nansen data sections; color shading indicates the number of the sections available in each month along the Angolan coast in the period from 1995 to 2013.

To check the frequency of the occurrence of the southward coastal current at the surface, the Oscar velocities were examined. Although the near coastal velocities derived from geostrophy are highly uncertain, they were found to correspond quite well to the 
advection of the low-salinity water from the Congo River. However, the correspondence between the negative salinity anomaly and the southward flow is not significant. Figure 6 shows the coastal salinity anomaly averaged between $6^{\circ} \mathrm{S}$ and $9^{\circ} \mathrm{S}$, together with the CRD, the sea-level anomaly (SLA) and the meridional velocity (V), all averaged between $6^{\circ} \mathrm{S}$ and $10^{\circ} \mathrm{S}$. V and SLA were band-pass filtered in the band of the coastal trapped waves from 20 to 130 days [5] to highlight the role of the intraseasonal variability. The southward flow is usually associated with the high SLA, at least in the first 3 months of the year and in Oct/November. For a strong negative propagating coastal salinity anomaly to occur (2016 and 2018) it seems to be necessary that several circumstances coincide: a strong CRD in the preceding December, which was not the case in 2011, 2013, 2014, or 2017. The southward flow modulated by the occurrence of a CTW has to be in time to advect the relative freshwater of riverine origin, which was not the case in 2012, though there was a strong southward flow later that year and a strong CRD. In 2014, there was a southward flow on time, but a weaker CRD. The year of 2015 had a considerable CRD, a southward flow on time, and, thus, a weak negative salinity anomaly. In 2016, the strong CRD was some days later than usual, and a strong southward flow was able to advect the low-salinity water southward. The strongest CRD in the last 40 years occurred at the end of 2019 due to anomalous high precipitation in the Congo Basin over the African continent. However, the negative salinity anomaly was not advected southward; instead, it spread into the western direction, as will be presented in the following.

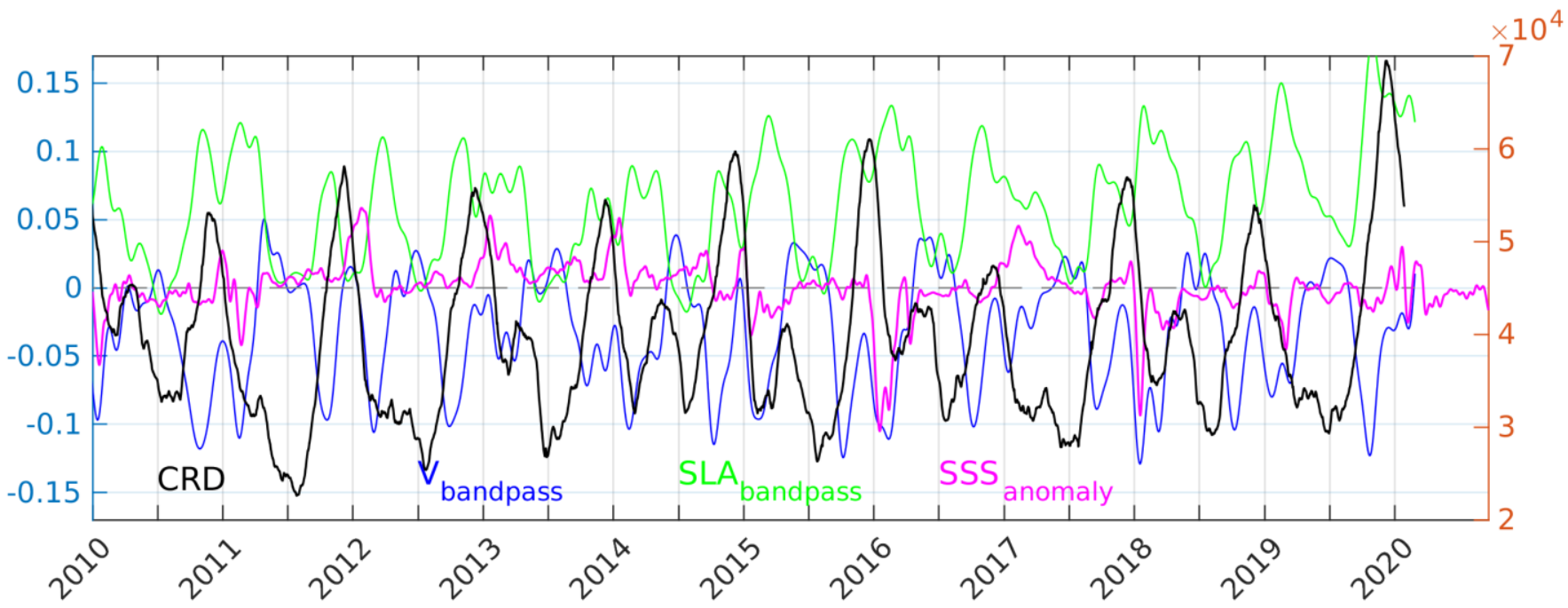

Figure 6. Timeseries of Congo River discharge (CRD, black line), alongshore velocity (V, blue line) and sea-level anomaly (SLA, green line), both bandpassed between 20 and 130 days, and coastal seasonal SSS anomaly (pink), all values averaged between $6^{\circ} \mathrm{S}$ and $10^{\circ} \mathrm{S}$. Left axis shows the units of the quasi-meridional velocity in $\mathrm{m} / \mathrm{s}$, the SLA in $\mathrm{m}$, and the SSS anomaly divided by 50 . The right axis shows the units for the CRD in $\mathrm{m}^{3} / \mathrm{s}$.

The secondary negative salinity anomaly in October was weaker; however, a southward flow usually also occurs in that month, advecting the low-salinity water southward (compare with Figure 4). The period from 2011 to 2013 shows a very small CRD during the austral winter, weakening the salinity signal along the coast despite the potential advection by the southward flow. In late 2019 , the negative salinity anomaly was stronger than in the years before, associated with a strong southward flow and a strong positive SLA, indicative of an anomalously warm season. After the work in Reference [43], there was a pronounced relationship between the meridional transport in the $\mathrm{AC}$ and the negative WSC on a seasonal time scale in the northern BUS. We only found a negative WSC anomaly in the coastal region off the Angolan coast in 2016 and 2018 (not shown), explaining the 
stronger southward Angola Current. However, a southward flow also existed in other years, without a negative WSC anomaly.

To explain the existence of interannual anomalies of the Congo River freshwater plume (either to the west or the south) the precipitation, the CRD and the advection were inspected concerning their interannual variability: the CRD was found to exert the strongest contribution of the freshwater forcing in the study area. The seasonal evolution of the run-off correlates well with the seasonal occurrence of the freshwater plume (Figure 3). The authors of [10] attributed 50\% of the decrease in salinity in a box off the Congo River mouth to the river runoff, which we can confirm. The interannual variability of local precipitation was analyzed here to rule out potential causes of a negative SSS anomaly due to anomalous strong precipitation. In the area off the Congo River mouth, a box between $10^{\circ} \mathrm{S}$ and $4^{\circ} \mathrm{S}, 5^{\circ} \mathrm{E}$ to the coast, we averaged the amount of precipitation from various datasets and computed the seasonal anomalies. The area receives precipitation in December to May, with the strongest rainfall usually occurring during March/April. The IMERG data showed a stronger precipitation than GPCP or Persiann data, with differences that may have also resulted from the differing spatial resolution. The monthly anomalies reflect the intermittency of stronger rainfall in weekly timescales. However, the maxima of unusually high precipitation was $250 \mathrm{~mm}$ per month (not shown). Using a gross estimation of the influence of $0.25 \mathrm{~m}$ freshwater on a column of a mixed layer with a depth of $15 \mathrm{~m}$ and a mixed-layer salinity of 34.5, the strongest potential decrease in salinity per month due to its precipitation was 0.23 , which was too low for the precipitation to be responsible for the strong salinity anomaly.

The authors of [10] showed that the advection's contribution to the climatological salinity budget is subject to high uncertainties. Their arbitrary choice of the velocity dataset did not explain the reason for this uncertainty. However, it is impossible to establish the salinity budget in the box, due to the lack of available in situ data. Therefore, the authors of [10] used a climatological setting to establish at least a gross estimate of the processes. The depth of the mixed-layer and the vertical processes are unknown, to close the budget. We limited our study of the processes leading to the change in salinity in a box, similar to the one chosen by [10], to the terms of advection motivated by Figure 6, which shows the strong interannual variability of the low-salinity plume and the alongshore currents. The mixed-layer salinity change in a box can be calculated following Reference [10], with:

$$
\frac{\partial S}{\partial t}=-u \cdot \frac{\partial S}{\partial x}-\mathrm{v} \cdot \frac{\partial S}{\partial y}+\frac{\mathrm{E}-\mathrm{P}-\mathrm{R}}{\mathrm{H}} S-\frac{1}{H} W\left(S-S_{H}\right)+\text { Residuals }
$$

Here, $S$ is the salinity of the mixed layer and is assumed to be equal to the satellitederived surface salinity. $S_{H}$ is the salinity at the mixed-layer depth $H$. In the absence of sufficient profile data to calculate the mixed-layer depth in each month, the mean mixedlayer of the available data in the box of $H=16 \mathrm{~m}$ was used. We extracted the mean salinity at the depth of the mixed layer from the objectively analyzed EN4 dataset for each month. $\mathrm{E}$ is the mean evaporation, $\mathrm{P}$ the mean precipitation of the box and $\mathrm{R}$ the CRD averaged for the box. The Residuals contain all physical processes, e.g., the vertical and horizontal diffusion, and other vertical processes, which we will not address. We derived the vertical velocity $W$ at the base of the mixed layer from the continuity equation, using the Oscar velocities representative of the velocity in the mixed layer, i.e.,

$$
W=H\left(\frac{d u}{d x}+\frac{d v}{d y}\right)
$$

Only upward (entraining) velocities were used because a downward velocity would not contribute to a change in the mixed-layer salinity. We are aware of this budget being a very crude estimate; however, the aim here is not to close the budget, but to show the variability of the advection terms. The present exercise can be considered as an extension of the study of Reference [10]. We separated the velocity and SSS data into low- and a 
high-frequency parts by low-pass filtering the data with a ninety-days Hamming window: $u=\bar{u}+u^{\prime}, S=\bar{S}+S^{\prime}$, with the overbar presenting the low-passed velocity and salinity, and the prime presenting the high-frequency component. We noted that the terms $u^{\prime} \cdot \frac{\partial S^{\prime}}{\partial x}$ and $\bar{u} \cdot \frac{\partial S^{\prime}}{\partial x}$ are very small; only the terms $u^{\prime} \cdot \frac{\overline{\partial S}}{\partial x}$ and $v^{\prime} \cdot \frac{\overline{\partial S}}{\partial x}$ contributed to the advection term.

The advection term plays the dominant role in the budget, and the interannual variability is considerable. The external surface fluxes, precipitation and river runoff show a quite regular seasonally varying influence; however, the contribution of the CRD was highest at the end of 2016 and 2019, and lowest at the end of 2017. We noted that the precipitation was not as small as Berger et al. suggested; we found a contribution of up to $50 \%$ of the freshwater supply into the box considered in the precipitation months. The OAflux evaporation data were recalculated for recent years; we note that there is a stronger seasonal cycle after 2016 than before 2016; however, this was smaller than the seasonal cycle of precipitation. The CRD had its maximum in December, while the precipitation reached its maximum in January/February; therefore, both provided freshwater to the box from October to March.

Figure 7 shows the calculated terms during the decade of satellite salinity data. The salinity tendency is shown with the black curve, with a negative tendency in the months from September to February, caused by the surface fluxes and compensated by strong advection. The salinity tendency shows a strong peak in April. This maximum cannot be explained by the considered processes; neither horizontal advection nor mean vertical advection can explain this increase in salinity. The residuals in Reference [10] are at their maximum in the months from April to June, showing that, using observational data, we miss the main processes involved, which we presume to be the vertical processes during the upwelling season. Our crude estimate of the vertical advection is maximum in the month of April, especially in 2011, but we were not able to capture the processes that reestablish the high subtropical salinity.

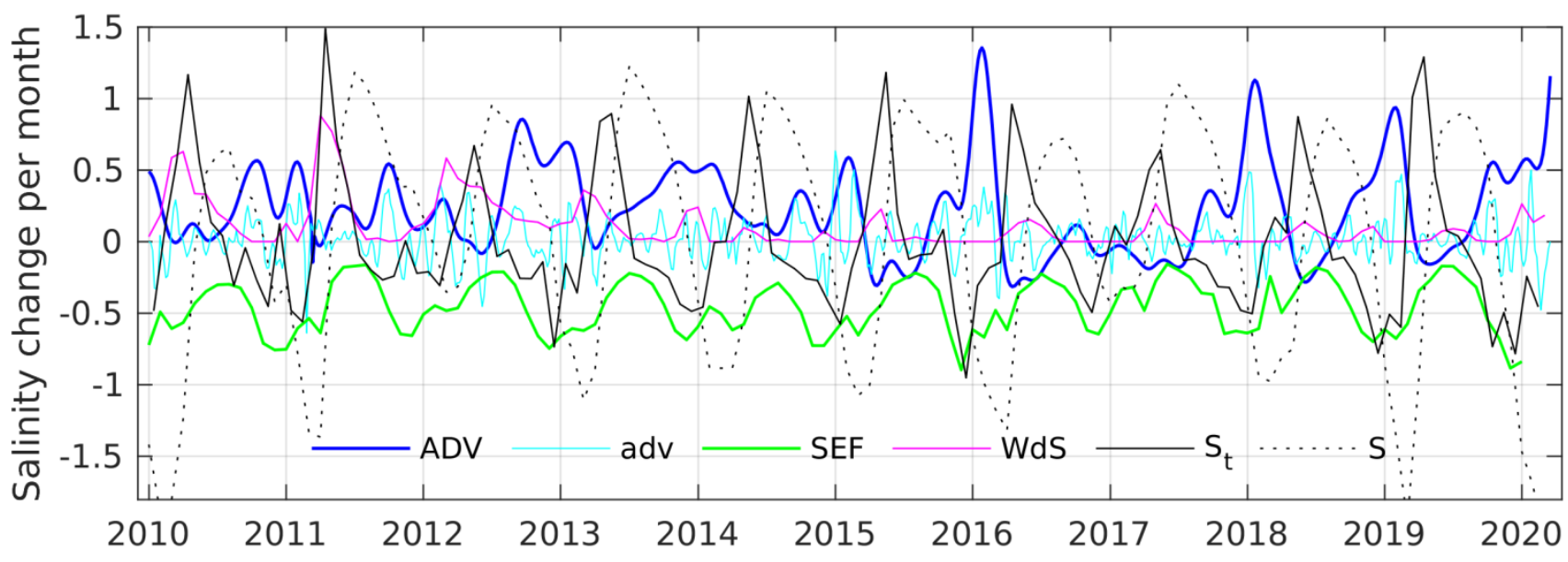

Figure 7. Time series of monthly averaged process terms of the salinity budget in the box between $5^{\circ} \mathrm{E}$ and the coast, and between $4^{\circ} \mathrm{S}$ and $10^{\circ} \mathrm{S}$ : ADV is the averaged advection calculated by the low-passed velocity and SSS data within the box (blue), adv is the corresponding high-frequency component of the velocity and the low-passed salinity (light blue), WdS is the monthly vertical advection of salinity across the mean mixed-layer depth (only positive; see text for further explanation). SEF are the external surface fluxes, i.e., the evaporation, precipitation and Congo River discharge, averaged for the box (green); the averaged salinity tendency is shown in the full black line, while the box-averaged salinity is shown in the broken black line (the total average of the salinity in the box (34.6) is subtracted). 


\subsection{Interannual Variability of SSS and NPP Anomalies}

The interannually varying extent of the Congo River plume is best identified during the months from January to April following the maximum discharge in December. To this end, we show 8 the deviations in SSS from the long-term mean in Figure 8. The seasonal SSS anomalies used above reveal strong positive anomalies due to temporal and spatial variability, e.g., a year with a strong southward extent of a fresh anomaly in February would lead to a positive anomaly in February of other years. Positive seasonal SSS anomalies are misleading, because the regional SSS is not strongly increasing, but only decreasing less. The negative SSS deviations from the long-term mean (blue color in Figure 8) are able to describe the spreading of the Congo River plume. Figure 8 reveals two main directions of spreading: the westward, mostly along $6^{\circ} \mathrm{S}$, and the coastal southward extension. A low-salinity tongue also occurs along the equator and $3^{\circ} \mathrm{S}$; this might be associated with the advection of equatorial low-salinity water, which is sometimes very separated from the low-salinity Congo plume (in 2014, 2015 and 2018), and sometimes merges not only with the CRD plume but also with the low-salinity waters in the GG. The low-salinity plume of the Congo is associated with NPP-positive anomalies (presented as contour lines in Figure 8), confirming its riverine origin. The spreading eventually only happens towards the west (in 2012, 2014 and 2017); in other years the plume is first advected southward along the coast and then veers westward (in 2011, 2016 and 2019), and follows both directions in 2015 and 2018. A fulminate spilling occurred all over the region in 2020 due to the exceptionally high CRD, caused by the strong precipitation at the end of 2019. The river plume seems to also partially extend to the north and joins the river runoff of the Ogooue from Gabun and the low-salinity water near the equator. Clear positive NPP anomalies also spread offshore the Angolan coast during the secondary maximum of CRD from October to November of the years 2014, 2015, 2017 and 2018, whereas, in the years 2010, 2016 and 2019 , clear negative NPP anomalies occurred in the offshore region (not shown).

The black contours in Figure 8 show the occurrence of a positive SST anomaly (only SST anomalies exceeding $1^{\circ} \mathrm{C}$ are shown), revealing the Atlantic or Benguela Niños in 2011 and 2016. Benguela Niños are defined by SST anomalies exceeding the STD(SST) in the area off the Angolan coast over 3 months [44]. Therefore, the weak anomaly in 2018 is not considered a Benguela Niño. Benguela Niños mainly occur in the downwelling season from January to April [45], although they may also occur in October/November. There was a Benguela Niño from October to December 2019 (not shown in this Figure, but analyzed in Reference [46]). Positive NPP anomalies are associated with the negative SSS anomalies; however, we cannot associate specific patterns of the plume extent with the Benguela Niños. We merely state that there is stronger coastal poleward flow in the spring months of 2016 and 2011, which are both associated with the spread of the low-salinity water; however, the poleward flow in 2015 and 2018 is associated with a very weak advection of low-salinity water in 2015, and no positive temperature anomaly, and only a weak positive SST anomaly in 2018. The positive NPP anomalies in 2011, 2015, 2016 and 2018 do not survive into the following upwelling months of July and August; in contrast, the NPPs in the July and August of 2011, 2015, 2016 and 2018 were anomalously weak. 

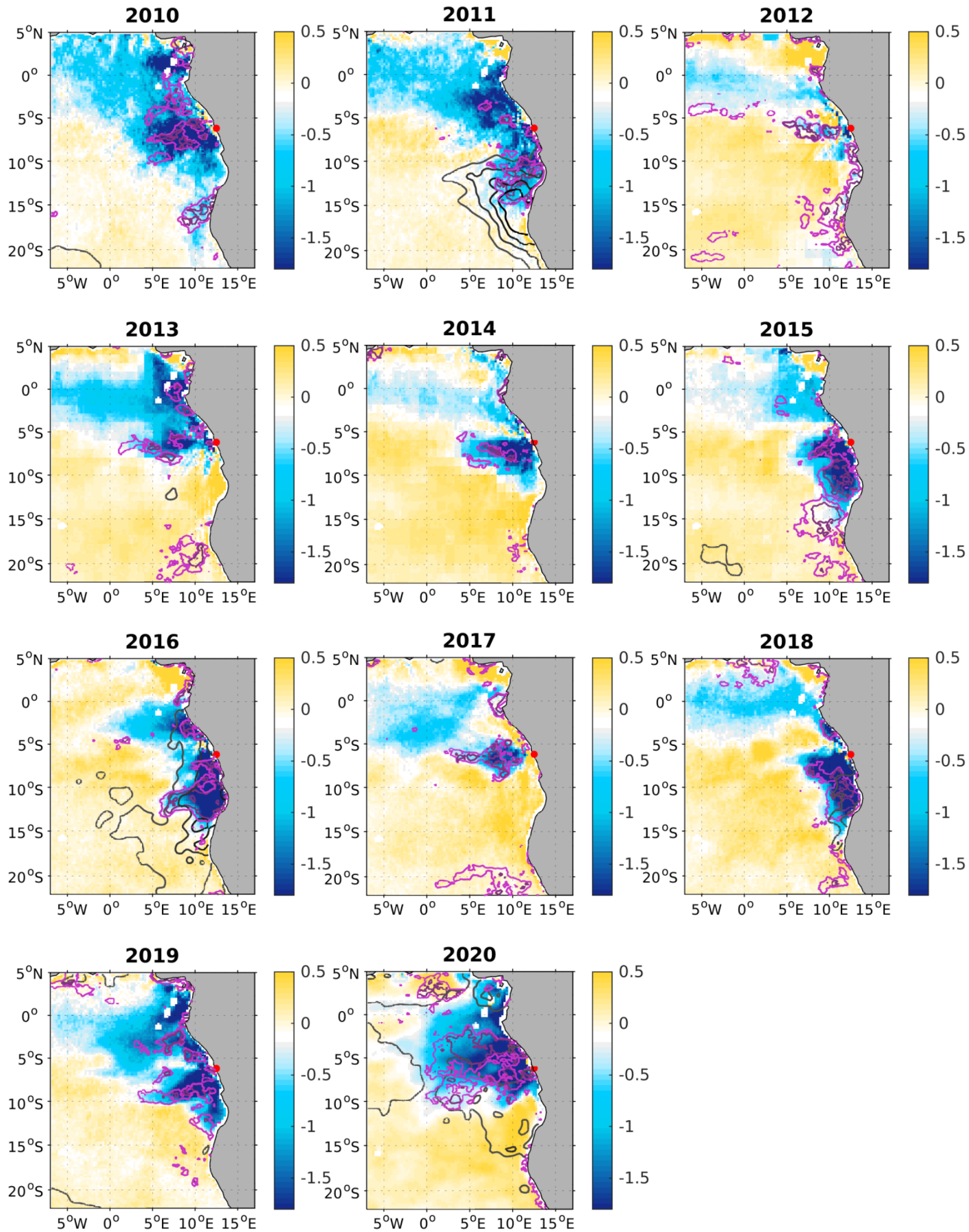

Figure 8. Yearly anomalies of satellite-derived parameters during the last 11 years, averaged in the months from January to April: In color, the deviations from the yearly mean SSS: higher SSS than usual in yellow to orange; lower SSS in blue (shading); only positive NPP anomalies are shown in pink contours (contour line at $0.1 \mathrm{mg} / \mathrm{m}^{3}$ in light pink and $0.2 \mathrm{mg} / \mathrm{m}^{3}$ in dark pink); grey to black contours show only positive SST anomalies (grey contours start at $+1.0^{\circ} \mathrm{C}$ and evolve to black contours at $2.5^{\circ} \mathrm{C}$ with an increment of $0.5^{\circ} \mathrm{C}$ ); the red dot presents the Congo River mouth. 


\subsection{Hydrographical Consequences}

The layer of low-salinity and high-temperature spilling from the Congo River mouth and spreading in the eastern tropical Atlantic is assumed to change the regional hydrography, i.e., influence the depth of the mixed layer and the stability of the water column, with consequences for the heat budget and mixing and entrainment from below. These processes are very difficult to observe and can only be deduced from enough in situ profiles. Some studies dealing with the freshwater budget have already been mentioned, e.g., Reference [10]: they show that, in this coastal region, the contributions of mixing and entrainment cannot be accessed by the available in situ data. Indications of high stability due to the freshwater layering are given by the Brunt-Väisälä frequency $N^{2}$, with $N^{2}=\frac{g}{\rho} \frac{\partial \rho}{\partial z}$ ( $\rho$ being density and $g$ the gravity acceleration). The in situ profiles of the Nansen cruises and all Argo profiles in the region were used to investigate the seasonal development of the water-column stability. Along the African coast, the Nansen expeditions provide a high data density, so the influence along the southward spreading of the river plume can be shown (Figure 9): The stability is higher, i.e., the $\mathrm{N}^{2}$ values were higher in the average March than in August, when taking all years of available data into account. The black contours in Figure 9 show the same isopycnals in March (upper panel) and August (lower panel) and reveal the upwelling along the coast between $6^{\circ} \mathrm{S}$ and $10^{\circ} \mathrm{S}$; further south, the upwelling phases seem to be very variable. An indication of the presence of upwelling can be seen in the $N^{2}$ maximum, which was slightly shallower in August than in March. The high potential available energy, due to the salinity stratification, can be illustrated by comparison with profiles with a constant salinity in the upper layer, which is relevant for the internal waves [22].
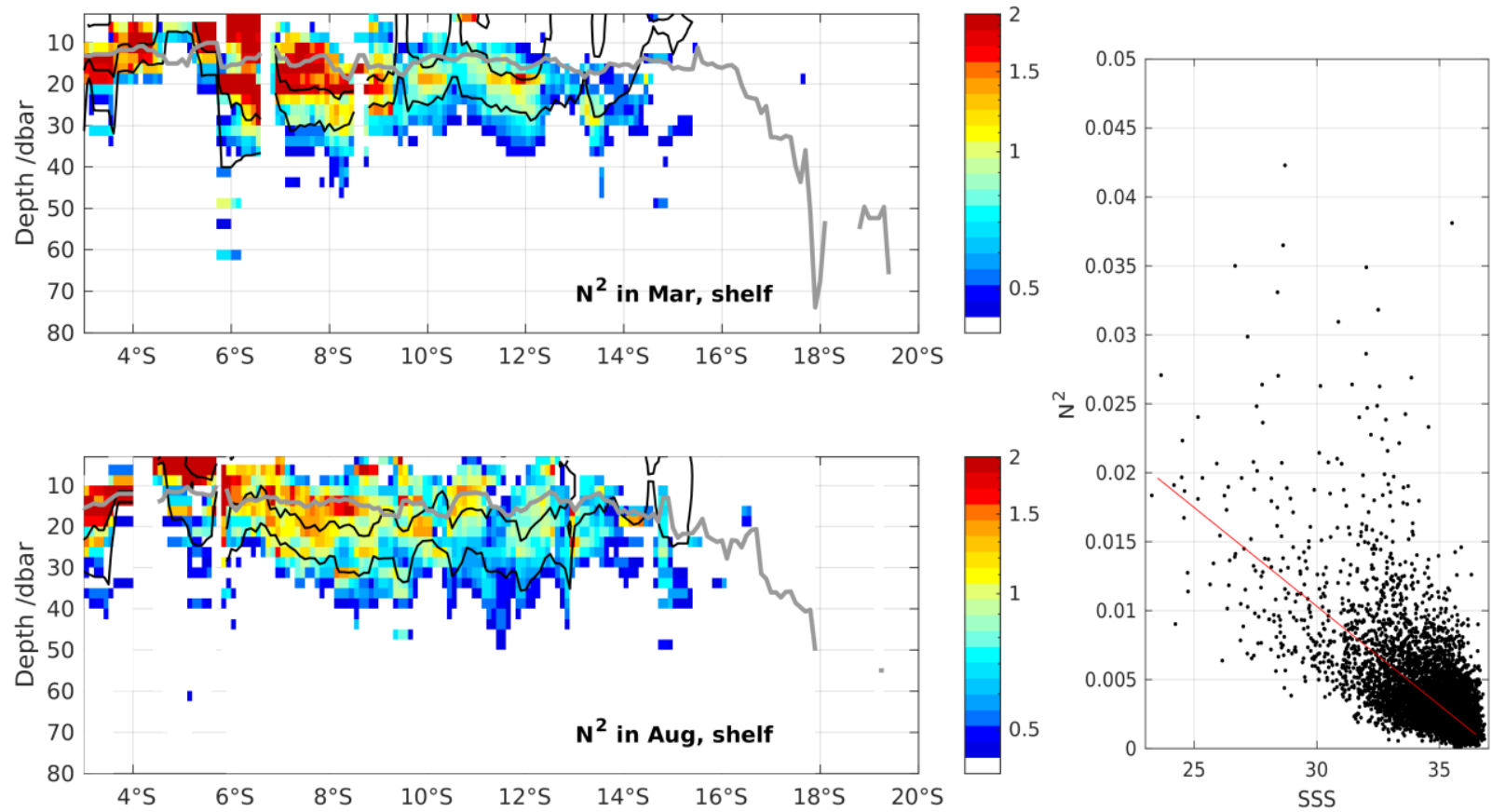

Figure 9. Zonally averaged values of $N^{2}$ off the Angolan coast to a distance of $200 \mathrm{~km}$ from available in situ data during March (upper panel) and August (lower panel) from 2005 to 2020 (note the logarithmic color bar). The Mixed-Layer Depth is drawn in grey, and the contour of 2 potential densities $\left(\sigma_{\theta}=23.5\right.$ and 24.5$)$ are shown in black. Right panel: Scatter diagram of uppermost salinity and the $N^{2}$ maximum derived from Argo profiles in the area between $4^{\circ} \mathrm{S}$ and $15^{\circ} \mathrm{S}$ and east of $5^{\circ} \mathrm{E}$.

The relation between the maximum $N^{2}$ and the low salinity at the surface is shown in Figure 9, right panel. The significant and clear relationship underlines the effect of the low-salinity plume on increasing the stability of the water column. 
The plume distribution strongly varied over the years, so that it was difficult to obtain enough profile data for a section in the open ocean. Instead, the development of the stratification is shown along the trajectory of an exemplary, selected Argo profiler. In Figure 10, the salinity along the trajectory of an exemplary Argo profiler is shown, with the mixed-layer depth derived from the density $\left(\mathrm{ML}_{\mathrm{r}}\right.$, blue) and temperature $\left(\mathrm{ML}_{\mathrm{t}}\right.$, black) profile. The difference between both is the barrier layer $\left(B L=M L_{t}-M L_{r}\right)$. Periods of low salinity (other than red) due to the Congo River plume are associated with the occurrence of a barrier layer; however, this only occurs eventually and is only thin (up to $10 \mathrm{~m}$ ). Eventually, the BL becomes thicker, as in October 2015. The stratification becomes sharper with the low-salinity layer on top, and $N^{2}$ increases. It is notably higher in March than in October, confirming the result of Figure 9. However, the existence of a higher BL can neither be clearly related to lower SSS nor to a stronger stratification ( $N^{2}$ maximum).

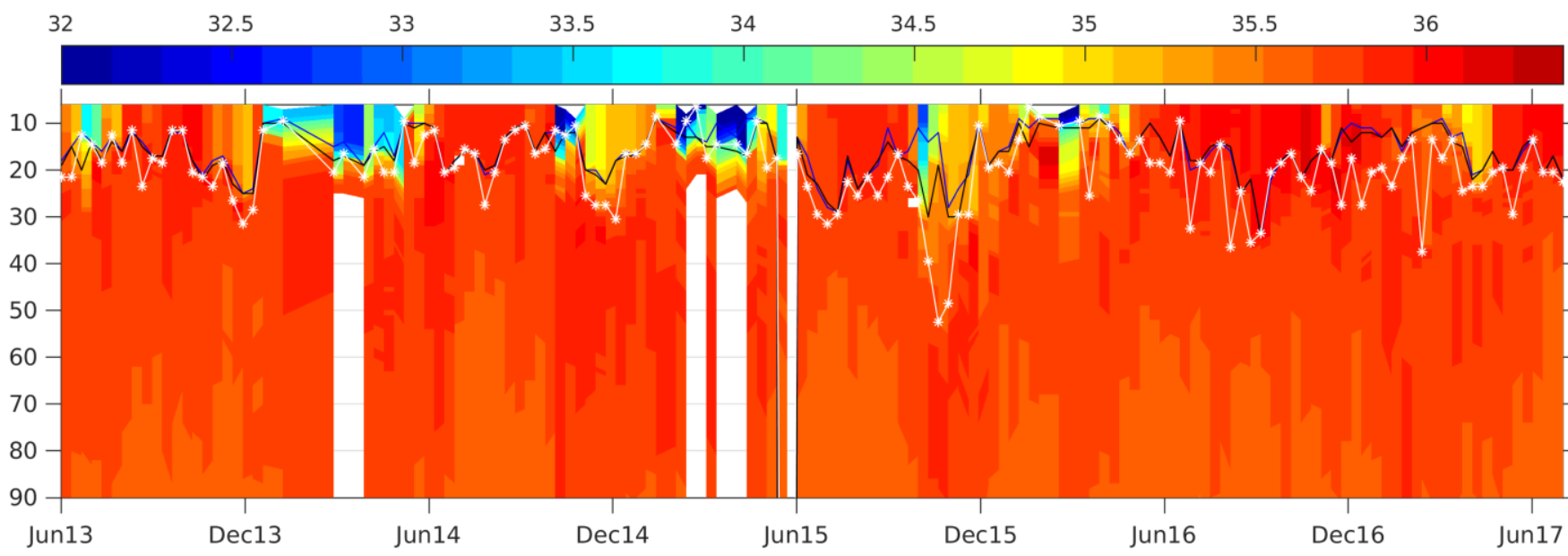

Figure 10. Salinity (shading) along the trajectory of an Argo no 6901452 near the Angolan coast from June 2013 to August 2017 (colorbar on top). The depth of the mixed isothermal layer, $\mathrm{ML}_{\mathrm{t}}$ (isopynal layer, $\mathrm{ML}_{\mathrm{r}}$ ) is shown by the black (blue) line. The depth of the maximum $N^{2}$ value is plotted by the white line with little stars. The position of this Argo profiler from Jan to Apr of each year is indicated in Figure 11 by the pink line.

Figure 11 shows the positions of all Argo profilers in the months from January to April in each year, as indicated by the grey dots. Interestingly, the profilers hardly exit the region, i.e., the ocean velocity at the drifting depth of $1000 \mathrm{~m}$ is very small. Drift presumably occurs presumably in the upper layers. This behavior allows the evolution of the hydrography during the spreading of the plume to be observed (indicated by the blue contour lines, corresponding to the blue anomalies in Figure 8). Some cases of a barrier layer were found in the presence of the low-salinity plume, also evolving near to the plume. With the Nansen dataset near to the coast, many BL cases were detected. However, a thick BL of more than $6 \mathrm{~m}$ off the coast is rarely found and cannot always be associated with the presence of the low-salinity layer. Moreover, the hypothesis of the existence of a strong BL during the anomalously warm episodes in the case of a Benguela Niño, e.g., in 2011 or 2016, cannot be proven. There were some Argo profiles in these 2 years, but a BL thicker than $6 \mathrm{~m}$ was found only sporadically. The north- and eastward advection of the subsurface-salinity maximum (South Atlantic Central Water) in July/August, below the relatively low salinity on top, may also lead to the formation of a BL. A systematic approach to the existence of the $\mathrm{BL}$ associated with the low-salinity plume is not possible, due to the sparse measurements. 

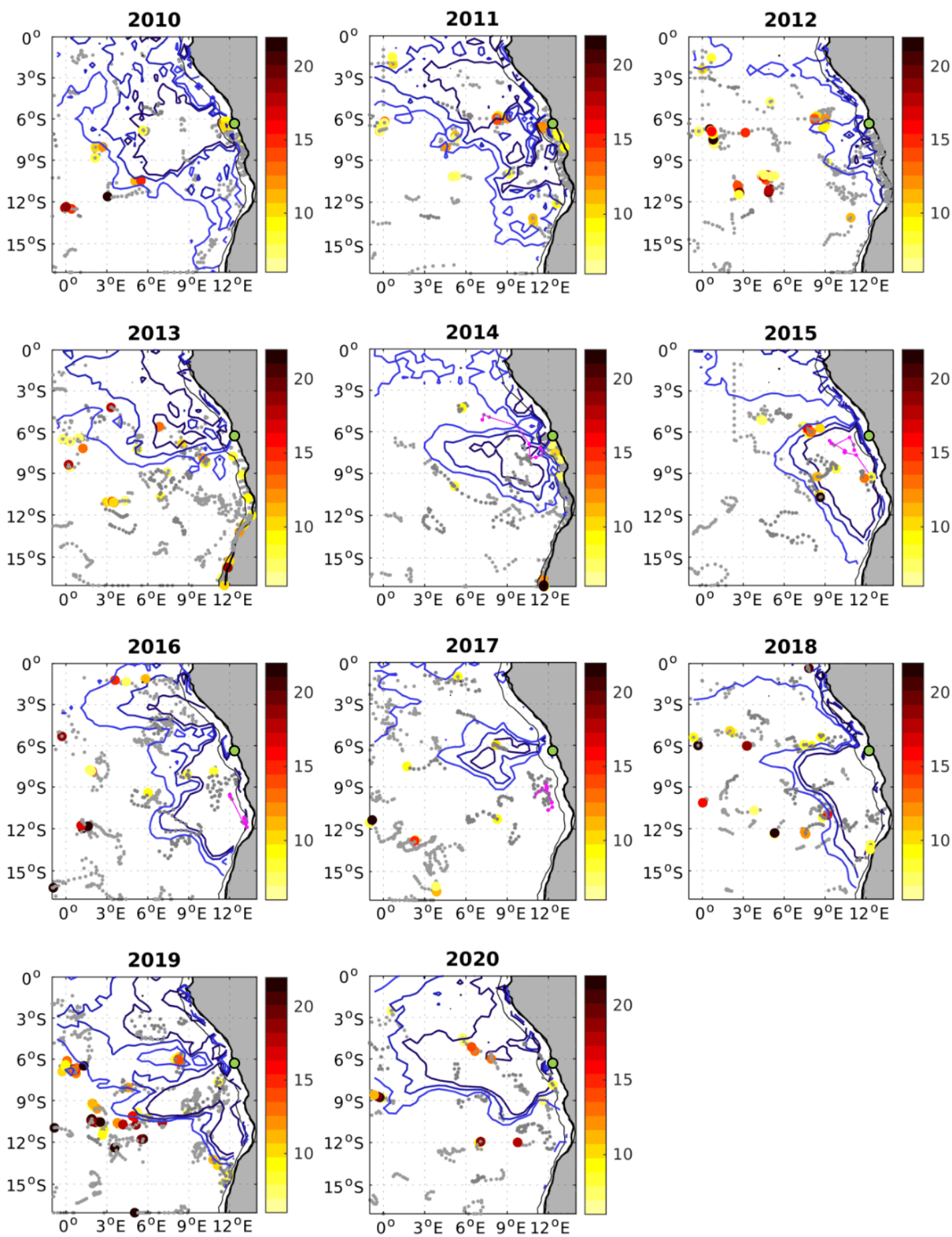

Figure 11. Positions of quality-checked Argo profilers during the indicated year from January to April (small grey dots), with the presence of barrier layers $>6 \mathrm{~m}$ (colored dots). Blue contours (at $-0.5,-1.0$ and -1.5$)$ indicate the negative salinity anomalies averaged for the months from January to April of each indicated year, corresponding to the blue shading in Figure 8. Black thin lines indicate the topography in the ocean region off Angola; the green dot represents the mouth of the Congo River; pink is the trajectory of the Argo profiler presented in Figure 10).

We conclude that the development of a barrier layer may influence the heat budget, as hypothesized in [3]; however, the events are rare and observations are difficult and based on hazard, so this cannot be quantified or proven. The strength of the river plume 
impact on the potential BL thickness is also dependent on the direction of the precipitationevaporation flux, rather than on the strength of the river flow [46].

The Angola current carrying the equatorial warm water poleward along the southwestern African coast results in less cooling and even stronger heating due to the top fresh layer. All available profiles in the study region were examined relative to the modification to the stratification of the water column and, e.g., the existence and thickness of a barrier layer. There is evidence from the available in situ profiles that a barrier layer occasionally exists; however, the geographical distribution shows a minimum number of profiles with barrier layers in the latitudinal range of the Congo river's freshwater plume. The existence of a barrier layer is not associated with a negative salinity anomaly ( $4 \%$ of the profile show a BL and a negative salinity anomaly; however, $4 \%$ also show a positive salinity anomaly), or a positive temperature anomaly. However, it is more likely for barrier layers to occur in the plume area of low salinity in March and April than in other months of the year. This result depends on the distribution of the CTD profiles in the area, which itself is dependent on the season. The Nansen CTD sections were predominantly carried out from February to April, and June to August, seldom carried out in May or October and never carried out from November to January, so the annual cycle was not completely covered.

In summary, the evidence of the barrier layer occurrence due to the low-salinity water of the Congo River plume could not be proven; however, it also could not be excluded. This is mostly due to the lack of data. The mixed layer is very thin, and the barrier layer that was found is very thin, too. Profiles with a BL showed thicknesses from 1 to $3 \mathrm{~m}$, and rarely exceeded $10 \mathrm{~m}$, which can only be assessed with a high-vertical-resolution that has only become available in recent years.

\section{Discussion}

All the results derived from in situ observations presented for the area off the Angolan coast suffer from the sparseness of data. The complete calculation of the salinity budget is not possible because barely estimable processes such as vertical upwelling and mixing are relevant in this upwelling area and cannot be neglected. The re-establishment of the high salinity in May to July could only be explained by considering advection and surface fluxes. The establishment of the barrier layer in the eastern tropical Atlantic is difficult to assess with the data available. We used a very generous criterion to detect the barrier layer in single profiles. Nevertheless, a systematic detection is difficult to achieve. High-resolution models may help in this respect (see Reference [31] for the barrier layer in a high-resolution circulation model); however, most models use a relaxation to climatological salinity, which itself suffers from the lack of data and does not present the realistic salinity variability. In this context, the assimilation of the satellite-derived sea-surface salinity certainly will represent an advance in our knowledge and understanding of the processes. Moreover, the internal tides are assumed to play a relevant role in the mixing at the shelf break, which is not included in most models. The representation of the SSS in reanalysis models was not studied in detail. Instead, this will be a subject of a separate study.

The Nansen dataset revealed many details in the hydrography and its variability during the 19 years of observations. Due to the strong fishery activities in this region, the maintenance of a long-term mooring is difficult and expensive. However, we rely on all kinds of in situ observations, to combine these with satellite measurements.

The coastal trapped waves propagating along the coast of South Africa comprise a wide frequency band and have different origins; some appear to be remotely forced by equatorial Kelvin waves, while some seemed to be locally forced by changes in coastal wind stress. They superpose and seem to influence the coastal velocities. We concentrated our study on band-passed velocity and SLA between 20 and 130 days. The correlation between these time series was found to be weak, because the interannual variability was strong. A study that is more dedicated to the special role of the CTW in advecting the salinity anomaly southward could highlight the origin and forcing of each wave in each year; however, this kind of study would fill the present study with even more details. Our 
focus was to present the dispersion of the surface-salinity anomalies not only into the western, offshore direction, but also into the coastal, poleward direction and its effects on the hydrography, which was possible with the unique Nansen in situ dataset and the innovative ESA CCI salinity data.

\section{Conclusions}

In this study, we used satellite-derived sea-surface salinity data to expand our knowledge about sea-surface variability off the coast of Africa, where we studied the variability of the Congo-River-induced freshwater plume and its interannual variability over the period from 2010 to 2020. The causes for the interannual variation in the freshwater plume extent were identified as variations in precipitation, variations in the rivers discharge and changes in ocean processes such as horizontal advection or vertical mixing. With the help of maps of satellite-derived SSS, we were able to show that the freshwater plume is not only spreading into the westward direction along $6^{\circ} \mathrm{S}$, but under certain conditions, is also advected in a southward direction. We were able to identify the causes of low-salinity anomalies spreading southward: a strong river discharge, combined with the existence of coastally trapped waves between February and March. The absence of either of these two conditions would prevent the southward extent of the plume. No significant coherence could be found between the southward spreading of the low-salinity water with temperature anomalies, indicating that the low-salinity water is merely advected southward by the surface current, but represents a surface pattern. However, no systematically thicker barrier layer could be detected in the first months of the year, nor could this be evidenced for their more frequent occurrence due to the freshwater plume.

Our study is just one an example of the knowledge that can be gained when sufficient information is available about the variability in the surface salinity of the ocean. Without the existence of satellite-derived SSS information, this would not be possible, and we anticipate that, with a continuation of satellite-based SSS information, much more insight could be gained regarding changes in the hydrological cycle and its influence on the ocean. This will be even more true, once the surface information is combined with in situ data and numerical models so that a full dynamical analysis can be made of what is going on in the eastern Atlantic Ocean and its upwelling regions. This analysis would also involve a quantification of the importance of mixing and other small-scale processes in shaping the flow field and its variations, which we were only able to hypothesize here.

Author Contributions: Conceptualization, M.S.M. and D.S.; methodology, software and validation, M.S.M.; writing-original draft preparation, M.S.M.; writing-review and editing, funding acquisition, D.S. All authors have read and agreed to the published version of the manuscript.

Funding: This research was supported in part through the BANINO project funded by the BMBF (FKZ 03F0795C).

Acknowledgments: We thank the ICDC, CEN, University of Hamburg for data support. This publication uses the WHOI OAFlux datasets supported by the NOAA's Global Ocean Monitoring and Observing (GOMO) Program and NASA's Making Earth System Data Records for Use in Research Environments (MEaSUREs) Program. The origins of all other data are stated in Section 2.

Conflicts of Interest: The authors declare no conflict of interest.

\section{References}

1. Shannon, L.V.; Boyd, A.J.; Brundrit, G.B.; Taunton-Clark, J. On the existence of an El Niño-type phenomenon in the Benguela system. J. Mar. Res. 1986, 44, 495-520. [CrossRef]

2. Bachèlery, M.-L.; Illig, S.; Rouault, M. Interannual Coastal Trapped Waves in the Angola-Benguela Upwelling System and Benguela Niño and Niña events. J. Mar. Syst. 2020, 203, 103262. [CrossRef]

3. Lübbecke, J.F.; Brandt, P.; Dengler, M.; Kopte, R.; Lüdke, J.; Richter, I.; Martins, M.S.; Tchipalanga, P.C.M. Causes and evolution of the southeastern tropical Atlantic warm event in early 2016. Clim. Dyn. 2019, 53, 261-274. [CrossRef]

4. Richter, I.; Behera, S.; Masumoto, Y.; Taguchi, B.; Komori, N.; Yamagata, T. On the triggering of Benguela Niños: Remote equatorial versus local influences. Geophys. Res. Lett. 2010, 37, 20604. [CrossRef] 
5. Illig, S.; Bachèlery, M.-L. Propagation of Subseasonal Equatorially-Forced Coastal Trapped Waves down to the Benguela Upwelling System. Sci. Rep. 2019, 9, 5306. [CrossRef]

6. Bachèlery, M.; Illig, S.; Dadou, I. Interannual variability in the South-East Atlantic Ocean, focusing on the Benguela Upwelling System: Remote versus local forcing. J. Geophys. Res. Oceans 2016, 121, 284-310. [CrossRef]

7. Materia, S.; Gualdi, S.; Navarra, A.; Terray, L. The effect of Congo River freshwater discharge on Eastern Equatorial Atlantic climate variability. Clim. Dyn. 2012, 39, 2109-2125. [CrossRef]

8. Denamiel, C.; Budgell, W.P.; Toumi, R. The Congo River plume: Impact of the forcing on the far-field and near-field dynamics. J Geophys. Res. Oceans 2013, 118, 964-989. [CrossRef]

9. Chao, Y.; Farrara, J.D.; Schumann, G.; Andreadis, K.M.; Moller, D. Sea surface salinity variability in response to the Congo river discharge. Cont. Shelf Res. 2015, 99, 35-45. [CrossRef]

10. Houndegnonto, O.J.; Kolodziejczyk, N.; Maes, C.; Bourlès, B.; Da-Allada, C.Y.; Reul, N. Seasonal Variability of Freshwater Plumes in the Eastern Gulf of Guinea as Inferred from Satellite Measurements. J. Geophys. Res. Oceans 2021, 126, e2020JC017041. [CrossRef]

11. Dossa, A.; Da-Allada, C.; Herbert, G.; Bourlès, B. Seasonal cycle of the salinity barrier layer revealed in the northeastern Gulf of Guinea. Afr. J. Mar. Sci. 2019, 41, 163-175. [CrossRef]

12. Eisma, D.; van Bennekom, A. The Zaire river and estuary and the Zaire outflow in the Atlantic Ocean. Neth. J. Sea Res. 1978, 12, 255-272. [CrossRef]

13. Dessier, A.; Donguy, J.R. The sea surface salinity in the tropical Atlantic between $10^{\circ} \mathrm{S}$ and $30^{\circ} \mathrm{N}-$ Seasonal and interannual variations (1977-1989). Deep Sea Res. Part I 1994, 41, 81-100. [CrossRef]

14. Bingham, F.M.; Foltz, G.R.; McPhaden, M.J. Characteristics of the seasonal cycle of surface layer salinity in the global ocean. Ocean Sci. 2012, 8, 915-929. [CrossRef]

15. Martins, M.S.; Serra, N.; Stammer, D. Spatial and temporal scales of sea surface salinity variability in the Atlantic Ocean. J. Geophys. Res. Oceans 2015, 120, 4306-4323. [CrossRef]

16. Fournier, S.; Lee, T. Seasonal and Interannual Variability of Sea Surface Salinity Near Major River Mouths of the World Ocean Inferred from Gridded Satellite and In-Situ Salinity Products. Remote Sens. 2021, 13, 728. [CrossRef]

17. Spencer, R.G.M.; Stubbins, A.; Gaillardet, J. Geochemistry of the Congo River, Estuary, and Plume. In Biogeochemical Dynamics at Major River-Coastal Interfaces: Linkages with Global Change; Bianchi, T.S., Allison, M.A., Cai, W.-J., Eds.; Cambridge University Press: Cambridge, UK, 2013; pp. 554-583. [CrossRef]

18. Cadée, G. Particulate and dissolved organic carbon and chlorophyll A in the Zaire river, estuary and plume. Neth. J. Sea Res. 1984, 17, 426-440. [CrossRef]

19. Hopkins, J.; Lucas, M.; Dufau, C.; Sutton, M.; Stum, J.; Lauret, O.; Channelliere, C. Detection and variability of the Congo River plume from satellite derived sea surface temperature, salinity, ocean colour and sea level. Remote Sens. Environ. 2013, 139, 365-385. [CrossRef]

20. Köhl, A.; Martins, M.S.; Stammer, D. Impact of assimilating surface salinity from SMOS on ocean circulation estimates. J. Geophys. Res. Oceans 2014, 119, 5449-5464. [CrossRef]

21. Santini, M.; Caporaso, L. Evaluation of Freshwater Flow from Rivers to the Sea in CMIP5 Simulations: Insights from the Congo River Basin. J. Geophys. Res. Atmos. 2018, 123, 10278-10300. [CrossRef]

22. Zeng, Z.; Brandt, P.; Lamb, K.G.; Greatbatch, R.J.; Dengler, M.; Claus, M.; Chen, X. Three-Dimensional Numerical Simulations of Internal Tides in the Angolan Upwelling Region. J. Geophys. Res. Oceans 2021, 126, e2020JC016460. [CrossRef]

23. Tchipalanga, P.; Dengler, M.; Brandt, P.; Kopte, R.; Macuéria, M.; Coelho, P.; Ostrowski, M.; Keenlyside, N.S. Eastern Boundary Circulation and Hydrography Off Angola: Building Angolan Oceanographic Capacities. Bull. Am. Meteorol. Soc. 2018, 99, 1589-1605. [CrossRef]

24. Reul, N.; Grodsky, S.; Arias, M.; Boutin, J.; Catany, R.; Chapron, B.; D’Amico, F.; Dinnat, E.; Donlon, C.; Fore, A.; et al. Sea surface salinity estimates from spaceborne L-band radiometers: An overview of the first decade of observation (2010-2019). Remote Sens. Environ. 2020, 242, 111769. [CrossRef]

25. Boutin, J.; Reul, N.; Koehler, J.; Martin, A.; Catany, R.; Guimbard, S.; Rouffi, F.; Vergely, J.L.; Arias, M.; Chakroun, M.; et al. Satellite-Based Sea Surface Salinity Designed for Ocean and Climate Studies. J. Geophys. Res. Oceans 2021, 126, e2021JC017676. [CrossRef]

26. Hersbach, H.; Bell, B.; Berrisford, P.; Hirahara, S.; Horanyi, A.; Muñoz-Sabater, J.; Nicolas, J.; Peubey, C.; Radu, R.; Schepers, D.; et al. The ERA5 global reanalysis. Q. J. R. Meteorol. Soc. 2020, 146, 1999-2049. [CrossRef]

27. Huffman, G.J.; Stocker, E.F.; Bolvin, D.T.; Nelkin, E.J.; Tan, J. GPM IMERG Final Precipitation L3 Half Hourly 0.1 Degree $\times$ 0.1 Degree V06, Greenbelt, MD, Goddard Earth Sciences Data and Information Services Center (GES DISC). Available online: https://doi.org/10.5067/GPM/IMERG/3B-HH/06 (accessed on 24 November 2021).

28. Adler, R.; Wang, J.-J.; Sapiano, M.; Huffman, G.; Chiu, L.; Xie, P.P.; Ferraro, R.; Schneider, U.; Becker, A.; Bolvin, D.; et al. Global Precipitation Climatology Project (GPCP) Climate Data Record (CDR), Version 2.3 (Monthly). Available online: https: / / doi.org/10.7289/V56971M6 (accessed on 20 October 2021).

29. Yu, L.; Weller, R.A. Objectively Analyzed air-sea heat Fluxes for the global ice-free oceans (1981-2005). Bull. Am. Meteorol. Soc. 2007, 88, 527-539. [CrossRef] 
30. Good, S.A.; Martin, M.J.; Rayner, N.A. EN4: Quality controlled ocean temperature and salinity profiles and monthly objective analyses with uncertainty estimates. J. Geophys. Res. Oceans 2013, 118, 6704-6716. [CrossRef]

31. Saha, A.; Serra, N.; Stammer, D. Growth and Decay of Northwestern Tropical Atlantic Barrier Layers. J. Geophys. Res. Oceans 2021, 126, e2020JC016956. [CrossRef]

32. Nicholson, S.E. The ITCZ and the Seasonal Cycle over Equatorial Africa. Bull. Am. Meteorol. Soc. 2018, 99, 337-348. [CrossRef]

33. Berger, H.; Treguier, A.M.; Perenne, N.; Talandier, C. Dynamical contribution to sea surface salinity variations in the eastern Gulf of Guinea based on numerical modelling. Clim. Dyn. 2014, 43, 3105-3122. [CrossRef]

34. Alsdorf, D.; Beighley, E.; Laraque, A.; Lee, H.; Tshimanga, R.; O’Loughlin, F.; Mahé, G.; Dinga, B.; Moukandi, G.; Spencer, R.G.M. Opportunities for hydrologic research in the Congo Basin. Rev. Geophys. 2016, 54, 378-409. [CrossRef]

35. Dai, A.; Qian, T.; Trenberth, K.E.; Milliman, J.D. Changes in Continental Freshwater Discharge from 1948 to 2004. J. Clim. 2009, 22, 2773-2792. [CrossRef]

36. Cook, K.H.; Liu, Y.; Vizy, E.K. Congo Basin drying associated with poleward shifts of the African thermal lows. Clim. Dyn. 2020, 54, 863-883. [CrossRef]

37. Rouault, M. Bi-annual intrusion of tropical water in the northern Benguela upwelling. Geophys. Res. Lett. 2012, $39,12606$. [CrossRef]

38. Ostrowski, M.; da Silva, J.C.B.; Bazik-Sangolay, B. The response of sound scatterers to El Niño- and La Niña-like oceanographic regimes in the southeastern Atlantic. ICES J. Mar. Sci. 2009, 66, 1063-1072. [CrossRef]

39. Gammelsrød, T.; Bartholomae, C.H.; Boyer, D.C.; Filipe, V.L.L.; O'Toole, M.J. Intrusion of warm surface water along the Angolan-Namibian coast in February-March 1995: The 1995 Benguela Nino. South Afr. J. Mar. Sci. 1998, 19, 41-56. [CrossRef]

40. Rouault, M.; Florenchie, P.; Reason, C.J.C.; Fauchereau, N. South East tropical Atlantic warm events and southern African rainfall. Geophys. Res. Lett. 2003, 30, 8009. [CrossRef]

41. Rouault, M.; Illig, S.; Bartholomae, C.; Reason, C.; Bentamy, A. Propagation and origin of warm anomalies in the Angola Benguela upwelling system in 2001. J. Mar. Syst. 2007, 68, 473-488. [CrossRef]

42. Kopte, R.; Brandt, P.; Dengler, M.; Tchipalanga, P.C.M.; Macuéria, M.; Ostrowski, M. The Angola Current: Flow and hydrographic characteristics as observed at $11^{\circ} \mathrm{S}$. J. Geophys. Res. Oceans 2017, 122, 1177-1189. [CrossRef]

43. Junker, T.; Schmidt, M.; Mohrholz, V. The relation of wind stress curl and meridional transport in the Benguela upwelling system. J. Mar. Syst. 2015, 143, 1-6. [CrossRef]

44. Koungue, R.A.I.; Rouault, M.; Illig, S.; Brandt, P.; Jouanno, J. Benguela Niños and Benguela Niñas in Forced Ocean Simulation from 1958 to 2015. J. Geophys. Res. Oceans 2019, 124, 5923-5951. [CrossRef]

45. Lübbecke, J.F.; Böning, C.W.; Keenlyside, N.; Xie, S.-P. On the connection between Benguela and equatorial Atlantic Niños and the role of the South Atlantic Anticyclone. J. Geophys. Res. Earth Surf. 2010, 115, 09015. [CrossRef]

46. Koungue, R.A.I.; Brandt, P.; Lübbecke, J.; Prigent, A.; Martins, M.S.; Rodrigues, R.R. The 2019 Benguela Niño. Front. Mar. Sci. 2021, 8, 800103. [CrossRef] 